LANGER, Máximo; LILLO, Ricardo, "Reforma a la justicia penal juvenil y adolescentes privados de libertad en Chile: Aportes empíricos para el debate".

Polít. crim. Vol. 9, № 18 (Diciembre 2014), Art. 13, pp. 713-738.

[http://www.politicacriminal.cl/Vol_09/n_18/Vol9N18A13.pdf]

\title{
Reforma a la justicia penal juvenil y adolescentes privados de libertad en Chile: Aportes empíricos para el debate*
}

\author{
Máximo Langer \\ Doctor of Juridical Science (S.J.D), Harvard University \\ Profesor de derecho, University of California Los Angeles (UCLA) \\ langer@law.ucla.edu \\ Ricardo Lillo \\ Master of Laws (LL.M) Specialization in Public Interest Law. University of \\ California Los Angeles (UCLA) \\ Profesor de derecho, Universidad Diego Portales \\ ricardo.lillo@mail.udp.cl
}

\section{Resumen}

Este artículo tiene por objeto brindar y analizar algunos datos empíricos sobre el funcionamiento de la Justicia Penal Adolescente luego de siete años de la entrada en vigencia de la Ley $\mathrm{N}^{\circ}$ 20.084. Uno de los objetivos de esta reforma fue adecuar la legislación en la materia a los estándares del Derecho Internacional de los Derechos Humanos, entre los cuales se encuentran el criterio de intervención penal especial reducida o moderada y la utilización de la privación de libertad como medida de ultima ratio. Nuestros datos indican que con posterioridad a su entrada en vigencia han aumentado tanto el número total de adolescentes privados de su libertad como la tasa relativa y la proporción de adolescentes privados de su libertad en comparación con los adultos. La conclusión de este estudio es que la reforma de la justicia penal juvenil, en su funcionamiento actual, probablemente ha contribuido a estos resultados. Sin embargo, este artículo no pretende agotar estos temas, sino más bien motivar una mayor investigación de tipo empírico que contribuya al debate público sobre este tema, así como promover la generación de mejores estadísticas por parte de las instituciones intervinientes.

Palabras clave: Justicia penal adolescente, datos empíricos, privación de libertad, Ley $\mathrm{N}^{\circ}$ 20.084 .

\begin{abstract}
This article aims at providing and analyzing empirical data regarding the criminal juvenile system in Chile seven years after the coming into effect of Act $\mathrm{N}^{\circ} 20084$ (which established the juvenile criminal responsibility system in Chile). One of the goals of this reform was to adequate the criminal juvenile justice legislation to international human

\footnotetext{
* Queremos agradecer a Mary Beloff, Marcelo Bergman, Jaime Couso, Mauricio Duce, Frank Zimring, y a los evaluadores anónimos de Política Criminal por sus comentarios sobre borradores anteriores de este trabajo.
} 
rights standards, that include the principles of exceptional and moderate use of criminal law and of using confinement only as ultima ratio. Our data indicate that after the coming into effect of the juvenile justice reform, the adolescent confinement rate has increased in absolute terms (i.e., in terms of the total number of adolescents in confinement) and in relative terms in comparison with the adult population in criminal confinement. We conclude that the criminal juvenile justice reform, as currently configurated, has probably contributed to this result.

Key words: Juvenile justice, empirical studies, juvenile confinement, Act $\mathrm{N}^{\circ} 20.084$ (Chile).

\section{Introducción}

Hace ya más de 7 años que entró en vigencia la reforma a la justicia penal para adolescentes en Chile. Esta reforma fue implementada mediante la nueva Ley $\mathrm{N}^{\circ} 20.084$ sobre Responsabilidad Penal Adolescente (Ley RPA) que modificó cómo y cuándo los adolescentes presuntamente infractores de ley son sometidos a la justicia penal.

Previamente, los menores de 18 años eran considerados como inimputables y sujetos a "medidas de protección", a menos que tuvieran 16 años o más y fueran declarados con discernimiento. En la práctica, estas medidas de protección eran medidas de privación de libertad tomadas bajo un procedimiento escrito y formalista. Dicho régimen fue criticado en Chile tanto por no respetar el debido proceso y por utilizar excesivamente la privación de libertad en contra de niños y adolescentes, como por ser ineficiente en la persecución penal de delitos cometidos por jóvenes. La nueva justicia penal para adolescentes vino entonces a ajustar la legislación a los estándares del Derecho Internacional de los Derechos Humanos y a introducir un régimen en donde estos jóvenes son considerados como penalmente responsables por sus actos, aunque sujetos a regulaciones específicas que toman en consideración que estas personas están en un proceso de desarrollo madurativo.

Si bien ha habido una importante literatura jurídica sobre esta reforma, casi no ha habido evaluaciones empíricas sobre los resultados de esta reforma. ${ }^{1}$ Este trabajo realiza un aporte

\footnotetext{
${ }^{1}$ Los estudios empíricos previos sobre la justicia penal de adolescentes luego de la reforma incluyen: DEPARTAMENTO DE ESTUDIOS, DEFENSORIA PENAL PÚBLICA, Informe Estadístico Primer año de vigencia Ley de Responsabilidad Penal Adolescente (8 junio 2007 a 7 junio 2008), Santiago: Defensoría Penal Pública, 2008; DEFENSORÍA PENAL PÚBLICA, 3 años de vigencia Ley de responsabilidad penal del adolescente 8 de Junio de 2007 a 7 de Junio de 2010. Santiago: Defensoría Penal Pública, 2011; BERRÍOS, Gonzalo, "La ley de responsabilidad penal del adolescente como sistema de justicia: análisis y propuestas", Polít. crim. Vol. 6, № 11, Art. 6 (2011), pp. 163-191; COUSO SALAS, Jaime; DUCE JULIO, Mauricio, Juzgamiento penal de adolescentes, Santiago: LOM ediciones, 2013; SENAME, Informe de Diagnóstico de la Implementación de la Ley 20.084 Junio 2007- Marzo 2010, Santiago: Sename, 2010. Pero salvo el primero de los documentos citados, los otros estudios no permiten realizar un análisis sobre los resultados de la reforma porque no incluyen datos sobre la justicia penal de adolescentes antes de la introducción de la reforma. La única excepción es el primer informe estadístico de la Defensoría Penal Pública aquí citado. Pero este informe estadístico solo cubre un periodo de dos años (un año anterior y un año posterior a la entrada en vigencia de la reforma) y no analiza el efecto de la reforma sobre los niveles de privación de libertad de adolescentes y adultos como hacemos en nuestro estudio.
} 
en esta dirección mediante la generación y presentación de datos sobre el funcionamiento empírico pre y post reforma de la justicia penal juvenil y la justicia penal de adultos en Chile. Nuestros datos indican que con posterioridad a la entrada en vigencia de la reforma penal juvenil ha habido una disminución en el porcentaje de adolescentes privados de su libertad de modo preventivo, pero también han aumentado tanto el número total de adolescentes privados de su libertad como la tasa relativa y la proporción de adolescentes privados de su libertad en comparación con los adultos privados de su libertad. Sobre este último punto es que se centra este análisis. Nuestra conclusión es que la entrada en vigencia de la reforma de la justicia penal juvenil ha probablemente contribuido a estos resultados. Pero este artículo no pretende agotar estos temas, sino más bien motivar una mayor investigación de tipo empírico en la materia en el mundo académico que contribuya al debate público sobre este tema, así como promover la generación de mejores estadísticas por parte de las instituciones intervinientes.

Con estos objetivos, este trabajo se divide en dos partes. En primer lugar, describiremos a grandes rasgos tanto el modelo tutelar regulado mediante la Ley de Menores vigente en Chile hasta el 2007 como la reforma a la justicia penal para adolescentes. A continuación, presentaremos datos empíricos de diversas instituciones para mostrar el impacto que ha tenido la reforma penal juvenil para los jóvenes infractores, y extraeremos algunas conclusiones que esperamos puedan motivar mayor investigación y discusión en la materia.

\section{El Sistema de Justicia Juvenil en Chile.}

En el mes de junio del año 2007 entró en vigor la Ley $N^{\circ} 20.084$ sobre Responsabilidad Penal Adolescente que introdujo profundos cambios a la manera en que eran tratados los jóvenes infractores de la ley penal bajo el hasta entonces vigente modelo tutelar establecido por la Ley $\mathrm{N}^{\circ} 16.618$ (también conocida como Ley de Menores). ${ }^{2}$

Esta Ley de Menores era aplicada a los menores de 16 años y a aquellos adolescentes de 16 y 17 años considerados como sin "discernimiento". Para este grupo, las únicas medidas a serles aplicadas tenían por objeto, en teoría, su protección. ${ }^{3}$ Para la determinación de la capacidad de discernimiento, los niños, niñas y adolescentes eran sometidos a un proceso judicial especial llevado ante un "Juez de Menores". Si los jóvenes de 16 y 17 años eran considerados con "discernimiento" en el Juzgado de Menores, estos eran enviados y sometidos al proceso penal regular bajo las mismas condiciones que un adulto.

De acuerdo a una investigación en la materia, del total de juveniles de 16 y 17 años que eran sometidos al procedimiento de la Ley de Menores, el $67.4 \%$ era declarado con discernimiento y el 32,6\% sin discernimiento (Tabla 1 ).

\footnotetext{
${ }^{2}$ Sobre la evolución del modelo tutelar y su influencia en Chile y América Latina, ver: CILLERO BRUÑOL, Miguel, "De la Tutela a las Garantías: Consideraciones sobre el Proceso Penal y la Justicia de Adolescentes", Revista de Derechos del Niño, $\mathrm{N}^{\circ} 2$ (2004), pp. 53-86.

${ }^{3}$ Ley 16.618 , artículo 28.
} 
LANGER, Máximo; LILLO, Ricardo, "Reforma a la justicia penal juvenil y adolescentes privados de libertad en Chile: Aportes empíricos para el debate".

\section{Tabla 1: Decisiones sobre Discernimiento bajo la Ley de Menores} $\underline{(2002)}$

\begin{tabular}{|c|c|c|}
\hline Con Discernimiento (\%) & Sin Discernimiento (\%) & Total (\%) \\
\hline $4342(67,4)$ & $2103(32,6)$ & 6445 \\
\hline
\end{tabular}

Fuente: Francisca Werth W., "Desafios y Características del Nuevo Sistema de Justicia Juvenil Chileno”, Fundación Paz Ciudadana, 2005.

El antiguo modelo de justicia penal para niños, niñas y adolescentes bajo la Ley $\mathrm{N}^{\circ} 16.618$ fue severamente criticado desde los años 90s en adelante. Una primer serie de críticas fue que el proceso inquisitivo que se utilizaba para perseguir y juzgar niños y adolescentes proceso también utilizado para adultos en Chile hasta el año 2005- era excesivamente formalista, lento, y carecía de garantías básicas del debido proceso. ${ }^{4}$ Una segunda serie de críticas se dirigió contra los aspectos sustantivos del modelo tutelar, argumentándose que creaba una percepción de impunidad en relación a los jóvenes infractores en un contexto de una alta sensación de inseguridad entre la población, no respetaba los derechos y garantías básicas de estos jóvenes, y utilizaba arbitraria y excesivamente la privación de libertad contra niños, niñas y adolescentes. ${ }^{5}$

Estas críticas llevaron a un proceso de reforma que tuvo por objeto la adecuación del sistema criminal de adolescentes tanto al sistema acusatorio implementado en Chile para adultos entre los años 2000 a 2005, como así también a los estándares específicos desarrollados en el campo del Derecho Internacional de los Derechos Humanos para jóvenes infractores, elemento clave tanto en la discusión pre-legislativa como posteriormente al interior del Congreso. ${ }^{6}$ En este sentido, la nueva Ley $\mathrm{N}^{\circ} 20.084$ reconoce en su artículo $2^{\circ}$ el interés superior del niño, niña o adolescente como el principal estándar aplicable en todo proceso judicial o administrativo, respecto tanto del procedimiento como de las sanciones o medidas. El artículo $2^{\circ}$ también señala expresamente que en la aplicación de la Ley $\mathrm{N}^{\circ}$ 20.084, las autoridades deben considerar todos los derechos y garantías establecidas en la Convención de los Derechos del Niño (CDN) y otros instrumentos internacionales ratificados por Chile.

Este proceso de reforma se cristalizó con la aprobación en el Congreso de la Ley $\mathrm{N}^{\circ}$ 20.084, que fue publicada en el Diario Oficial en el año 2005 y entró en vigencia en junio de 2007. Esta ley vino a establecer un modelo de responsabilidad en virtud del cual los jóvenes entre 14 y 17 años son considerados sujetos de derecho responsables por sus actos,

\footnotetext{
${ }^{4}$ Sobre el proceso de reforma a la justicia penal en Chile y las principales críticas al modelo inquisitivo, ver: RIEGO RAMÍREZ Cristian, "El Proceso de Reforma del Procedimiento Penal Chileno", en: HURTADO POZO, José (Dir.); SAN MARTÍN CASTRO, César (Coord.), La Reforma del Proceso Penal Peruano, Anuario de Derecho Penal 2004, Lima: Fondo Editorial de la Pontificia Universidad Católica del Perú, 2004, pp. 373-400.

${ }^{5}$ Ver, por ejemplo: BIBLIOTECA DEL CONGRESO NACIONAL DE CHILE, Historia de la Ley 20.084, Establece un sistema de responsabilidad de los adolescentes por infracciones a la ley penal, Santiago: Biblioteca del Congreso Nacional de Chile, 2005, pp. 5-7.

${ }^{6}$ BERRÍOS, “La ley de responsabilidad penal del adolescente", cit. nota n ${ }^{\circ} 1, \mathrm{p} .166$.
} 
pero bajo un régimen especial que reconoce que todavía no han terminado su proceso madurativo. ${ }^{7}$

La nueva legislación eliminó los antiguos Juzgados de Menores y estableció un sistema de justicia especializado en relación a la justicia penal de adultos. Con esta modificación se buscó implementar un tratamiento diferenciado entre adultos y adolescentes en el funcionamiento práctico de la justicia. ${ }^{8}$ Con estos fines, la propia Ley RPA estipula que, como regla general, aquellos jueces, fiscales y defensores públicos que manejen este tipo de infractores deben estar capacitados y especializados en la materia. ${ }^{9}$ Sin embargo, más allá de estas capacitaciones, no existe una especialización orgánica dado que los actores que intervienen en casos de adolescentes (tribunales, fiscales, defensores, policías), aun cuando especialmente capacitados, son los mismos que los del sistema penal para adultos. ${ }^{10}$

Otra consecuencia de la justicia especializada es que ahora las personas menores de 18 años deben ser privadas de libertad en instituciones especiales y diferentes de aquellas para adultos. La institución a cargo de la ejecución de las decisiones de los tribunales penales para estos casos es el Servicio Nacional de Menores (SENAME). La configuración de estos centros del SENAME difieren sustancialmente de los centros penitenciarios habituales, en particular porque estos tienen por objeto principal la rehabilitación y protección de niños, niñas y adolescentes vulnerables - no solo de aquellos que hayan cometido delitos- y porque sus administradores y equipos de trabajo tienden a ser profesionales de perfiles diversos - por ejemplo trabajadores sociales- que los de los guardias y administradores de las cárceles de adultos.

Como señalamos con anterioridad, el objetivo de la nueva normativa fue adecuar la legislación a los estándares del debido proceso estipulados tanto en la Constitución como en la CDN. ${ }^{11}$ Pero, además, la nueva legislación tuvo por objeto mejorar la eficiencia del sistema de justicia penal juvenil y dar protección a las víctimas y a la población general en el contexto de un aumento en la percepción de los delitos cometidos por menores de edad. ${ }^{12}$ En este sentido, hubo una clara tensión en la concepción misma del nuevo modelo entre el objetivo de proteger el debido proceso y los derechos de niños, niñas y adolescentes en conflicto con la ley versus el objetivo de aumentar la eficiencia en la persecución y el castigo de los delitos cometidos por adolescentes. ${ }^{13}$

${ }^{7}$ CORPORACIÓN OPCIÓN; UNICEF, ;Conoce Tus Derechos! Manual sobre la Ley de Responsabilidad Penal de Adolescentes, Santiago: UNICEF y Corporación Opción, 2009, p. 11.

${ }^{8}$ BERRÍ́OS, "La ley de responsabilidad penal del adolescente", cit. nota $\mathrm{n}^{\circ} 1, \mathrm{p} .169$.

${ }^{9}$ Ley $\mathrm{N}^{\circ} 20.084$, artículo 29.

${ }^{10}$ Sobre las deficiencias en el objetivo de una justicia especializada ver: ESPEJO YAKSIC, Nicolás, Hacia una Reforma Integral del Sistema Penal de Adolescentes en Chile: el Desafío de la Especialización, Serie reflexiones Infancia y adolescencia $N^{\circ} 18$, Santiago: UNICEF, 2014, p. 6.

${ }^{11}$ Ver: BIBLIOTECA DEL CONGRESO NACIONAL DE CHILE, Historia de la Ley 20.084, cit. nota n ${ }^{\circ}$, p. 5-7.

${ }^{12}$ Ver: BIBLIOTECA DEL CONGRESO NACIONAL DE CHILE, Historia de la Ley 20.084, cit. nota ${ }^{\circ}{ }^{5}$, p. 7-8.

${ }^{13}$ Sobre esta tensión, ver: CILLERO BRUÑOL Miguel; BERNALES, Martín, "Derechos humanos de la infancia/adolescencia en la justicia "penal de menores" de Chile: evaluación y perspectivas", Revista de Derechos del Niño, $\mathrm{N}^{\circ} 1$ (2002), pp. 9-40, pp. 31-33 (2002); CILLERO BRUÑOL, Miguel; ESPEJO YAKSIC, Nicolás, "Derechos de los Adolescentes Privados de Libertad en Chile: En búsqueda de la tutela 
LANGER, Máximo; LILLO, Ricardo, "Reforma a la justicia penal juvenil y adolescentes privados de libertad en Chile: Aportes empíricos para el debate".

De acuerdo a la historia de la Ley $\mathrm{N}^{\circ}$ 20.084, la idea fue, siguiendo estándares internacionales en la materia, establecer un criterio de intervención penal especial reducida o moderada, tanto en relación a los delitos, como a las sanciones aplicables a las personas en el rango de edad señalado por la Ley. ${ }^{14}$ Con ello, se buscó privilegiar un contacto mínimo o reducido del individuo con la justicia criminal de manera de “...evitar o mitigar los efectos desocializadores producidos al relacionar a un joven con el sistema penal, sin perjuicio de servir también a la descongestión de la administración de justicia". ${ }^{15}$

En consecuencia, la ley establece que la privación de libertad previa al juicio o con posterioridad a la sentencia debe ser usada como medida de última ratio, esto es, cuando no haya otra alternativa posible y nunca en los casos en los cuales tampoco sería apropiada para un adulto. ${ }^{16}$

Producto de lo anterior, la nueva legislación establece reglas claras para la determinación de la pena o de las medidas a adoptar, para limitar el uso arbitrario de la privación de libertad, lo cual era considerado uno de los aspectos problemáticos del antiguo sistema tutelar. ${ }^{17}$ En este sentido, uno de los elementos centrales del nuevo sistema es el respeto por el principio de legalidad. El Art. 40.2 (a) de la CDN establece este principio al disponer que los Estados Partes garantizarán “(q)ue no se alegue que ningún niño ha infringido las leyes penales, ni se acuse o declare culpable a ningún niño de haber infringido esas leyes, por actos u omisiones que no estaban prohibidos por las leyes nacionales o internacionales en el momento en que se cometieron".

A mayor abundamiento, en la propia historia de la ley RPA, se expone como motivo la reforma de un sistema que fallaba en el respeto a esta garantía fundamental mediante la utilización de fórmulas abiertas para la determinación de las sanciones privativas de libertad, como la irregularidad, los desajustes conductuales o el peligro material o moral. ${ }^{18}$ Así por ejemplo, el artículo 32 de la antigua Ley de Menores establecía que “...aunque se llegue a la conclusión de que el hecho no se ha cometido o que al menor no le ha cabido

judicial efectiva", Revista General de Derecho Penal, No 9 (2008), pp. 1-12; DUCE JULIO, Mauricio, "El proceso establecido en el Proyecto de Ley que crea un sistema de responsabilidad de los adolescentes por infracciones a la ley penal: avances y problemas", Revista de Derechos del Niño, N 2 (2004), pp. 99-114, pp. 111-112.

${ }^{14}$ BIBLIOTECA DEL CONGRESO NACIONAL DE CHILE, Historia de la Ley 20.084, cit. nota ${ }^{\circ}$ 5, p. 12.

${ }^{15}$ BERRÍOS, "La ley de responsabilidad penal del adolescente", cit. nota n ${ }^{\circ} 1$, p. 170.

${ }^{16}$ Ley $\mathrm{N}^{\circ} 20.084$, Artículo 26 (La privación de libertad se utilizará sólo como medida de último recurso. En ningún caso se podrá imponer una pena privativa de libertad si un adulto condenado por el mismo hecho no debiere cumplir una sanción de dicha naturaleza); Artículo 32 (La internación provisoria en un centro cerrado sólo será procedente tratándose de la imputación de las conductas que de ser cometidas por una persona mayor de dieciocho años constituirían crímenes, debiendo aplicarse cuando los objetivos señalados en el inciso primero del artículo 155 del Código Procesal Penal no pudieren ser alcanzados mediante la aplicación de alguna de las demás medidas cautelares personales). Acerca de estos y otros principios que debieran servir de guía para la interpretación de la nueva legislación en la materia por parte de los tribunales y otros actores del sistema, ver e.g., COUSO SALAS, Juzgamiento, cit. nota $n^{\circ} 1$.

${ }^{17}$ Ley $\mathrm{N}^{\circ} 20.084$, artículo 23.

${ }^{18}$ BIBLIOTECA DEL CONGRESO NACIONAL DE CHILE, Historia de la Ley 20.084, cit. nota n 5, pp. 67. 
participación alguna en él, el juez podrá aplicarle las medidas de protección que contempla esta ley, siempre que el menor se encontrare en peligro material o moral".

Además de regular estrictamente la manera en que se determinará la pena y el uso de la privación de libertad, ${ }^{19}$ se regulan en la ley RPA diversas modalidades de penas alternativas o no privativas de libertad de manera de reservar estas para casos de gravedad: amonestación, multas, la reparación del daño, servicios en beneficio de la comunidad, la prohibición de conducir vehículos motorizados, libertad asistida (sujeción del adolescente al control de un delegado conforme a un plan de desarrollo personal basado en programas y servicios que favorezcan su integración social), y la libertad asistida especial (asistencia del adolescente a un programa intensivo de actividades socioeducativas y de reinserción social en el ámbito comunitario que permita la participación en el proceso de educación formal, la capacitación laboral, la posibilidad de acceder a programas de tratamiento y rehabilitación de drogas en centros previamente acreditados por los organismos competentes y el fortalecimiento del vínculo con su familia o adulto responsable). ${ }^{20}$

Las sanciones privativas de libertad consisten en la internación en régimen cerrado o semicerrado. Ambas consisten en la privación de libertad del joven en un establecimiento administrado por el SENAME (con un máximo de 5 años para adolescentes de 14 y 15 años y de 10 años para aquellos de 16 y 17 años de edad), con la diferencia que mientras en el centro cerrado los internos permanecen en su interior todo el día, en el semicerrado deben efectuar actividades de reinserción fuera del recinto, al menos 8 horas al día. ${ }^{21}$

Además de hacer efectiva la responsabilidad de los adolescentes por los hechos delictivos que cometan, las sanciones deben formar parte de una intervención socioeducativa amplia y orientada a la plena integración social, sean o no sanciones privativas de la libertad. ${ }^{22}$

Otra consecuencia de la intervención penal reducida es que las condiciones en que es posible la privación de libertad preventiva, que en el marco de la Ley RPA es denominada internación provisoria, son limitadas. Esta internación solo procede tratándose de la imputación de conductas que de ser cometidas por una persona mayor de dieciocho años constituirían crímenes, y solo cuando los objetivos de la privación de libertad provisoria no pudieran ser alcanzados mediante la aplicación de otras medidas cautelares personales. ${ }^{23}$ Además, la internación provisoria debe cumplirse en recintos especiales del SENAME, llamados Centros de Internación Provisoria (CIP). ${ }^{24}$

Adicionalmente, se permite y promueve el uso de medidas o salidas alternativas al juicio, haciendo aplicables las normas del Código Procesal Penal en la materia en sede juvenil. ${ }^{25}$

\footnotetext{
${ }^{19}$ Ley $\mathrm{N}^{\circ} 20.084$, artículos 20-23.

${ }^{20}$ Ley $\mathrm{N}^{\circ} 20.084$, artículos 8-14.

${ }^{21}$ CORPORACIÓN OPCIÓN; UNICEF, ;Conoce Tus Derechos!, cit. nota n ${ }^{\circ}$ 7, p. 34.

${ }^{22}$ Ley $\mathrm{N}^{\circ} 20.084$, artículo 20.

${ }^{23}$ Ley $\mathrm{N}^{\circ} 20.084$, artículo 32.

${ }^{24}$ CORPORACIÓN OPCIÓN; UNICEF, ;Conoce Tus Derechos!, cit. nota n ${ }^{\circ}$ 7, p. 77.

${ }^{25}$ BERRÍOS, "La ley de responsabilidad penal del adolescente", cit. nota ${ }^{\circ} 1$, p. 170 .
} 
LANGER, Máximo; LILLO, Ricardo, "Reforma a la justicia penal juvenil y adolescentes privados de libertad en Chile: Aportes empíricos para el debate".

De esta manera, el fiscal tiene la posibilidad de no iniciar la investigación, de archivar el caso provisionalmente y de aplicar el denominado "principio de oportunidad". ${ }^{26}$

\section{Evaluación empírica del nuevo sistema de justicia penal de adolescentes.}

De la revisión de la literatura existente, es posible afirmar que si bien existen algunos estudios de carácter empírico que han tenido por objeto evaluar la reforma a la justicia penal adolescente, estos en su mayoría solo proveen y analizan datos sobre el funcionamiento de la justicia juvenil antes o después de la implementación, más que evaluar la reforma propiamente dicha. ${ }^{27}$ Nuestra estrategia, en cambio, es hacer una evaluación de la reforma que incluya información pre y post implementación de la reforma a la justicia penal adolescente y a su vez datos sobre el sistema de justicia penal de adultos para tener un punto de comparación con el tratamiento a los juveniles. ${ }^{28}$

En este sentido, nuestros datos indican que si bien los porcentajes de adolescentes en internamiento provisorio disminuyó luego de la entrada en vigencia de la reforma a la justicia penal juvenil, las tasas totales y relativas de privación de libertad de adolescentes han aumentado luego de la entrada en vigencia de la reforma a la justicia penal juvenil.

Antes de comenzar con el análisis de la reforma a la justicia penal juvenil, es importante señalar que un análisis de la privación de libertad versus los contactos formales con la policía de jóvenes y adultos sugieren que los jóvenes en Chile son privados de su libertad en menor medida que los adultos (Tabla 2), tal como ocurre en la mayoría de los países de América Latina. ${ }^{29}$

\footnotetext{
${ }^{26}$ CORPORACIÓN OPCIÓN; UNICEF, ;Conoce Tus Derechos!, cit. nota n ${ }^{7}$, p. 80.

${ }^{27}$ Como ya señalamos, la única excepción en este sentido es el reporte: DEFENSORIA PENAL PÚBLICA, Informe Estadístico, cit. nota ${ }^{\circ} 1$. Sin embargo, este reporte presenta datos sobre un corto período de tiempo que va desde un año antes a un año después de que la Ley RPA entrara en vigencia e incluye básicamente los casos llevados por dicha institución, sin tampoco analizar, como hacemos en este trabajo, los niveles de privación de libertad de jóvenes y adultos.

${ }^{28}$ Los datos que utilizaremos en esta sección fueron recolectados exclusivamente por Máximo Langer y Ricardo Lillo y utilizados anteriormente por Máximo Langer en el siguiente trabajo: BELOFF, Mary; LANGER, Máximo, "Myths and Realities of Juvenile Justice in Latin America", en: LANGER, Máximo; TANENHAUS, David S.; ZIMRING, Franklin D., (Compiladores), Juvenile Justice in Global Perspective: Estados Unidos: NYU Press, 2015 (en prensa).

${ }^{29}$ Sobre el menor uso de la privación de libertad de jóvenes que de adultos en la mayoría de los países de América Latina, ver: BELOFF/LANGER, "Myths and Realities", cit. nota n 28.
} 
Polít. crim. Vol. 9, No 18 (Diciembre 2014), Art. 13, pp. 713-738.

[http://www.politicacriminal.cl/Vol_09/n_18/Vol9N18A13.pdf]

Tabla 2: Números Totales y Porcentajes de Contactos Formales con la Policía y de Privaciones de Libertad de Adultos y Juveniles en Chile $\underline{(2008-2012)}$

\begin{tabular}{|c|c|c|c|c|c|}
\hline Dato & 2008 & 2009 & 2010 & 2011 & 2012 \\
\hline $\begin{array}{c}\text { Adultos en contacto formal con } \\
\text { la policía }\end{array}$ & 503575 & 556869 & 558373 & 554095 & 534168 \\
\hline Privación de libertad adultos & 48824 & 52947 & 54628 & 53606 & 49350 \\
\hline $\begin{array}{c}\text { Jóvenes en contacto formal con } \\
\text { la policía }\end{array}$ & 53386 & 51448 & 48033 & 57227 & 54932 \\
\hline Privación de libertad jóvenes & 1569 & 1750 & 1844 & 1690 & 1882 \\
\hline $\begin{array}{c}\text { Porcentaje de contactos formales } \\
\text { con la policía de adultos } \\
\text { respecto del total de contactos } \\
\text { formales con la policía }\end{array}$ & 90.4 & 91.5 & 92.1 & 90.6 & 90.7 \\
\hline $\begin{array}{c}\text { Porcentaje de privación de } \\
\text { libertad de adultos respecto del } \\
\text { total de privados de libertad }\end{array}$ & 96.9 & 96.8 & 97.7 & 96.9 & 96.3 \\
\hline $\begin{array}{c}\text { Porcentaje de jóvenes en } \\
\text { contacto formal con la policía } \\
\text { respecto del total de contactos } \\
\text { formales con la policía }\end{array}$ & 9.6 & 8.5 & 7.9 & 9.4 & 9.3 \\
\hline $\begin{array}{c}\text { Porcentaje de jóvenes privados } \\
\text { de libertad respecto del total de } \\
\text { privaciones de libertad }\end{array}$ & 3.1 & 3.2 & 3.3 & 3.1 & 3.7 \\
\hline
\end{tabular}

Fuente: United Nations Office on Drugs and Crime, Statistics on Criminal Justice

(http://www.unodc.org/unodc/en/data-and-analysis/statistics/data.html); DEPARTAMENTO DE ESTUDIOS, GENDARMERÍA DE CHILE, Compendio Estadístico Penitenciario, Santiago: Gendarmería de Chile, 20102012; SENAME, Boletín Estadístico Anual de los Niños(as) y Adolescentes Vigentes en la Red SENAME, 2003-2013, Santiago: Sename, 2003-2014

Los porcentajes de adultos y jóvenes en contacto formal con la policía (es decir, que han sido arrestados o citados o considerados sospechosos por la comisión de un delito por parte de la policía) respecto del total de contactos formales con la policía nos dan un acercamiento sobre cuántos adultos y jóvenes ingresan al sistema de justicia. Mientras que el porcentaje de jóvenes en contacto formal con la policía respecto del total de contactos formales con la policía es mayor que el porcentaje de jóvenes en privación de libertad respecto del total de privaciones de libertad registradas, el porcentaje de adultos en contacto formal con la policía es menor que el porcentaje de adultos en privación de libertad. Esta relación entre contactos formales con la policía y privación de libertad de adultos y jóvenes se observa en todos los años reportados en la Tabla 2 (2008 a 2012). Esto indica que los jóvenes son privados de libertad con menor frecuencia que los adultos en Chile. 
LANGER, Máximo; LILLO, Ricardo, "Reforma a la justicia penal juvenil y adolescentes privados de libertad en Chile: Aportes empíricos para el debate".

Figura 1. Proporción de privados de libertad respecto de contactos formales con la policía en adultos y jóvenes en Chile en 2008-2012

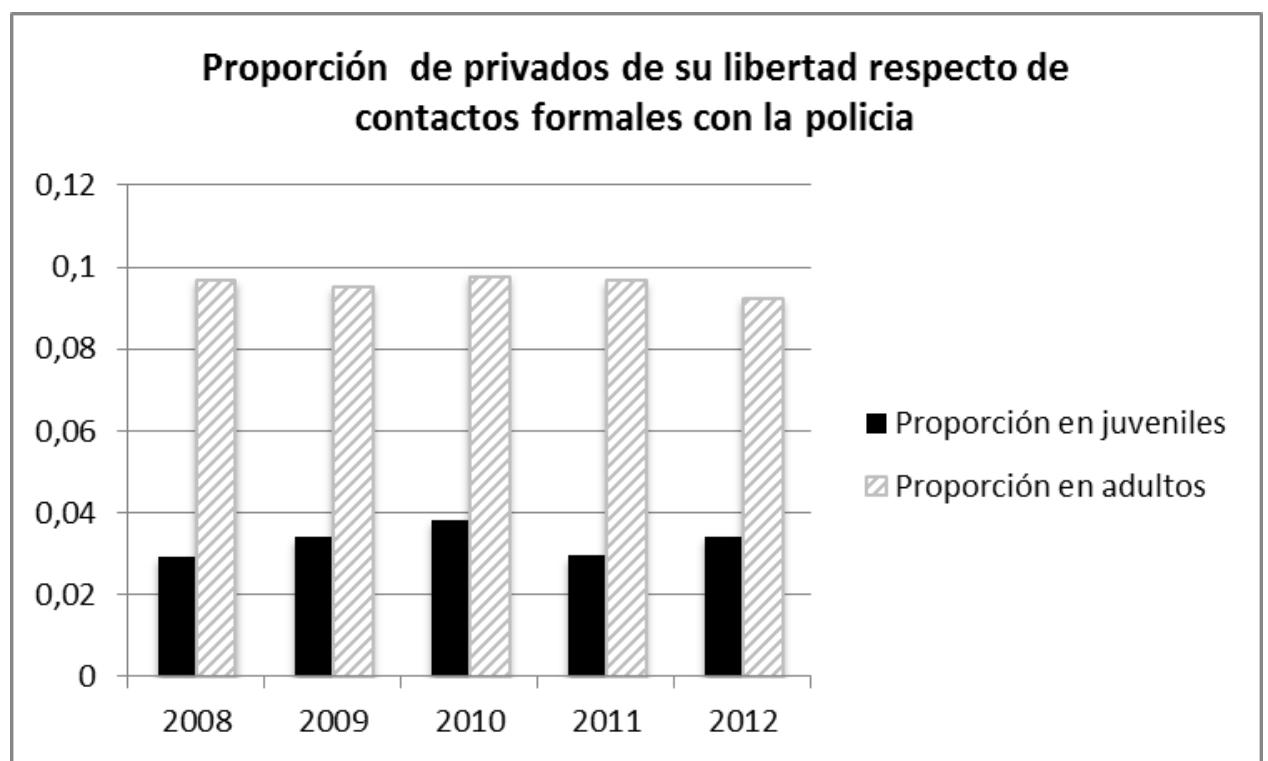

Fuente: United Nations Office on Drugs and Crime, Statistics on Criminal Justice (http://www.unodc.org/unodc/en/data-and-analysis/statistics/data.html); DEPARTAMENTO DE ESTUDIOS, GENDARMERÍA DE CHILE, Compendio Estadístico Penitenciario, Santiago: Gendarmería de Chile, 20102012.; SENAME, Boletín Estadístico Anual de los Niños(as) y Adolescentes Vigentes en la Red SENAME, 2003-2013, Santiago: Sename, 2003-2014

Desde otra perspectiva, en Chile la proporción de adultos privados de libertad versus aquellos en contacto formal con la policía fue 3.3 veces mayor a la de jóvenes privados de libertad versus jóvenes en contacto formal con la policía en 2008, y 2,69 veces mayor en 2012, teniendo la menor diferencia en 2010 al ser 2,55 veces mayor (Figura 1).

Dicho de otro modo, en el año 2008 hubo 10,3 adultos en contacto formal con la policía por cada adulto privado de su libertad, mientras que hubo 34 jóvenes en contacto formal con la policía por cada joven privado de su libertad. En el 2010, hubo 10,3 adultos versus 33,9 jóvenes en contacto formal con la policía y en el 2012 hubo 10,8 adultos versus 29,1 jóvenes en contacto formal con la policía por cada adulto y joven respectivamente privado de su libertad.

En general, de estos datos presentados es posible extraer que hay largas diferencias entre la proporción de adultos y jóvenes que han entrado en contacto con el sistema de justicia penal y terminan siendo privados de su libertad. El hecho de que los adultos que entran en contacto formal con la policía son en mayor proporción privados de su libertad que los niños y adolescentes que entran en contacto formal con la policía es un importante indicador de que, sin soslayar otros potenciales problemas que están más allá del objeto de este trabajo, la justicia juvenil en la práctica aplica, en cierta medida, el principio de mínima intervención. 
Sin embargo, aun cuando los niveles de privación de libertad son menores en relación a los adultos, para analizar los efectos de la reforma introducida por la RPA es necesario realizar una comparación de la situación pre y post reforma para conocer si la tendencia recién descrita existía antes de su entrada en vigencia y si los niveles de privación de libertad post reforma son menores que bajo el modelo tutelar.

En este sentido, realizaremos primero una comparación en el uso de la internación provisoria (término con el que la RPA se refiere a la prisión preventiva) versus la privación de libertad post sentencia judicial, tanto en el caso de los adolescentes como en el de los adultos, comparación que no había sido realizada hasta ahora. Esta es una tarea compleja, porque no sólo las medidas no han sido exactamente las mismas bajo el modelo tutelar y la Ley RPA, sino que además las instituciones encargadas de la supervisión de las medidas no han sido las mismas pre y post reforma (por lo que la manera en que las estadísticas han sido recogidas y sistematizadas también han diferido pre y post reforma). ${ }^{30}$

Con estos fines, hasta el 2006 (el año anterior a la entrada en vigencia de la Ley RPA) hemos considerado como jóvenes en prisión preventiva a aquellos menores de edad en Centros de Observación y Diagnóstico del SENAME, más aquellos reportados bajo el régimen de prisión preventiva en los informes de Gendarmería. Luego, hasta el 2006, hemos considerado como condenados aquellos en Rehabilitación Conductual Internado más aquellos reportados como condenados por Gendarmería. Para los datos del 2007, hemos tomado en consideración las mismas categorías, sumando aquellos en internación provisoria al dato sobre prisión preventiva, y a aquellos en internación en régimen cerrado y semicerrado al dato sobre condenados. A partir del 2008, usamos solo datos de SENAME respecto de jóvenes en internación provisorio y en internación en régimen cerrado y semicerrado.

Analicemos ahora los porcentajes de adultos y jóvenes en privación de libertad preventiva.

\footnotetext{
${ }^{30}$ Por ejemplo, mientras que los datos de gendarmería son reportados como promedio diario, los datos del SENAME reportados son los vigentes al 31 de diciembre de cada año.
} 
LANGER, Máximo; LILLO, Ricardo, "Reforma a la justicia penal juvenil y adolescentes privados de libertad en Chile: Aportes empíricos para el debate".

Figura 2: Porcentaje de jóvenes y adultos en prisión preventiva (o sus equivalentes) en Chile en 2003-2012

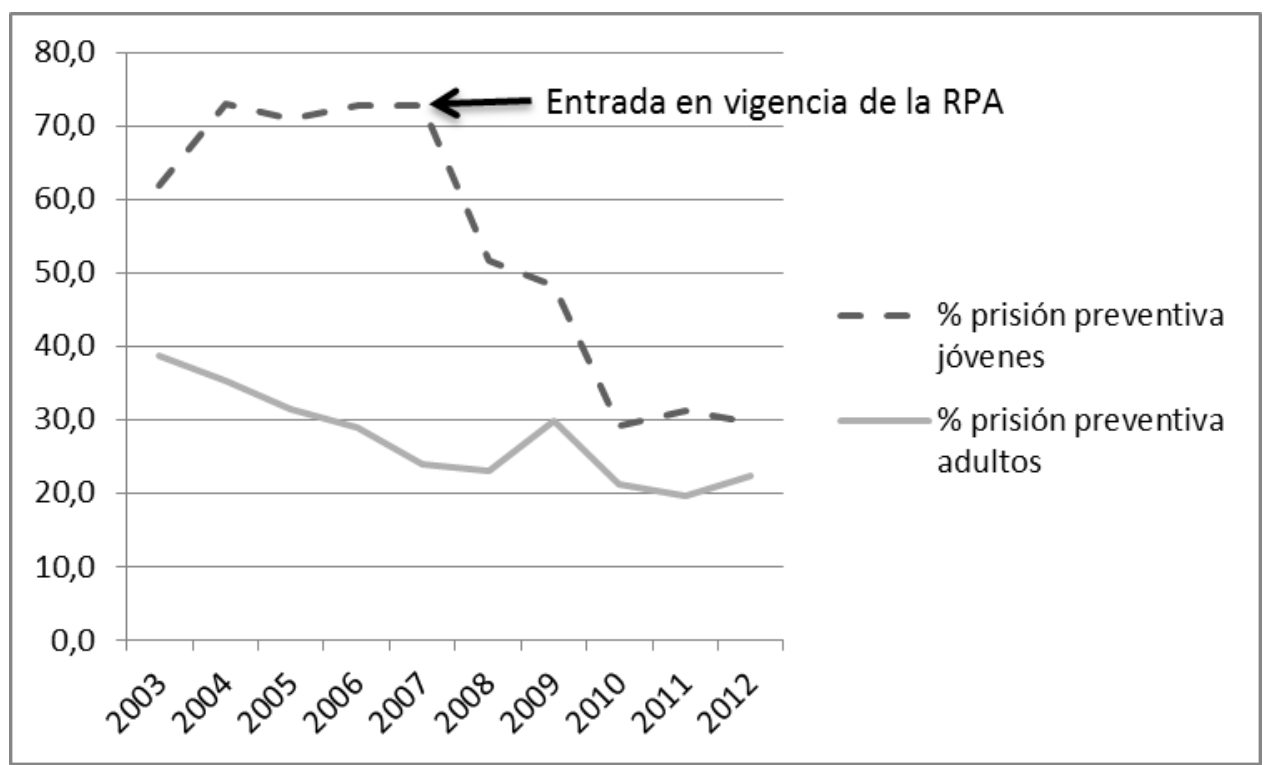

Fuente: DEPARTAMENTO DE ESTUDIOS, GENDARMERÍA DE CHILE, Compendio Estadístico Penitenciario, Santiago: Gendarmería de Chile, 2010-2012.; SENAME, Boletín Estadístico Anual de los Niños(as) y Adolescentes Vigentes en la Red SENAME, 2003-2013, Santiago: Sename, 2003-2014

Bajo el modelo tutelar, es decir previo a la entrada en vigencia de la Ley RPA en 2007, los porcentajes de jóvenes en prisión preventiva respecto de la población juvenil total privada de su libertad sobrepasaban el $70 \%$, prácticamente duplicando el porcentaje de adultos en prisión preventiva respecto de la población adulta total privada de su libertad. Estas cifras para adolescentes antes de la entrada en vigencia de la RPA eran incluso superiores al porcentaje de adultos en prisión preventiva antes del comienzo de la implementación gradual de la reforma procesal penal para adultos en el año $2000 .^{31}$ Sin embargo, aun cuando puede notarse el importante efecto de la entrada en vigencia de la Ley RPA (que implicó también la entrada de vigencia del sistema acusatorio del Código Procesal Penal ahora respecto de los adolescentes) en la disminución del porcentaje de jóvenes privados de su libertad preventivamente, la proporción de jóvenes en prisión preventiva es todavía superior a la de los adultos luego de la entrada en vigencia de la RPA (Figura 2).

Previamente a la reforma a la justicia penal adolescente, los niveles de privación de libertad de manera previa al juicio eran substancialmente mayores a la privación post sentencia. En este sentido, entre los años 2003 y 2006, los porcentajes de privación preventiva de los jóvenes oscilaban entre el $72 \%$ a $74,7 \%$ (Figura 2 ).

\footnotetext{
${ }^{31}$ En un estudio realizado por el Centro de Estudios de Justicia de las Américas (CEJA), Chile tenía un 51\% de personas en prisión preventiva respecto del total antes de la entrada en vigencia gradual del sistema acusatorio para adultos en el 2000. Ver: CENTRO DE ESTUDIOS DE JUSTICIA DE LAS AMÉRICAS (CEJA), Prisión Preventiva y Reforma Procesal Penal en América Latina. Evaluación y Perspectivas, Santiago: CEJA, 2009. Sobre el proceso de reformas acusatorias al proceso penal en América Latina, ver: LANGER, Máximo, Revolución en el Proceso Penal Latinoamericano: Difusión de Ideas Legales desde la Periferia, Santiago: Centro de Estudios de Justicia de las Américas (CEJA), 2008.
} 
Estos altos porcentajes de prisión preventiva (o sus equivalentes) pueden ser parcialmente explicados por el proceso inquisitivo vigente en esos años para los menores de edad. Este tipo de proceso, al ser escrito y formalista, tomaba mucho tiempo en pasar a la fase de juzgamiento $\mathrm{y}$, además, consideraba que la prisión preventiva era la regla más que la excepción durante la etapa investigativa. Sin embargo, dado que estos porcentajes de prisión preventiva eran mucho más altos para los niños y adolescentes que para los adultos en los años previos a la entrada en vigencia plena de la reforma procesal penal para adultos en el año 2005 (cuando el porcentaje de prisión preventiva de adultos era aproximadamente $30 \%),{ }^{32}$ puede que estos porcentajes tan altos para jóvenes también hayan sido producto del modelo tutelar. Dado que el modelo tutelar concebía la privación de libertad como una medida de protección para los juveniles, posiblemente era menos importante si estas medidas eran impuestas antes o después de la adjudicación formal en estos casos.

Desde que entró en vigencia la nueva justicia juvenil en 2007, la distribución entre privación de libertad pre y post sentencia ha cambiado drásticamente. En este período, el porcentaje de prisión preventiva cayó de 72,7\% en 2007 a 29,6\% en 2012 (Figura 2). Este resultado puede ser producto del sustancialmente menor tiempo de duración de los procesos o de una regulación más liberal de la prisión preventiva bajo el proceso acusatorio, tal como sucedió con la entrada en vigencia de la reforma procesal penal en el caso de los adultos. ${ }^{33}$ Esta disminución en el porcentaje de jóvenes en prisión preventiva puede ser considerado una mejora del RPA en términos de debido proceso dado que ahora la mayoría de los jóvenes en privación de libertad han sido encontrados culpables por el tribunal, cumpliendo los estándares de debido proceso del sistema acusatorio. ${ }^{34}$

Sin embargo, la Figura 3 muestra que el número total de jóvenes en privación de libertad no ha disminuido. En este sentido, el cambio en los porcentajes en la prisión preventiva de jóvenes es también el resultado del incremento sustancial en el número de jóvenes condenados privados de su libertad.

\footnotetext{
${ }^{32}$ Ver: GENDARMERÍA DE CHILE, Compendio Estadístico Penitenciario 2010, Santiago: Gendarmería de Chile, 2010, p. 29.

${ }^{33}$ Para un análisis de la evolución de la prisión preventiva en Chile de manera previa y posterior a la reforma procesal penal en Chile, ver: DUCE J., Mauricio; RIEGO R., Cristian, La Prisión Preventiva en Chile: Análisis de los Cambios Legales y su Impacto, Santiago: Ediciones Universidad Diego Portales, 2011.

${ }^{34}$ En este sentido, estas mejoras en debido proceso en Chile pueden considerarse relacionadas con las mejoras en debido proceso en Estados Unidos introducidas por casos como In Re Winship, 397 U.S. 358 (1970).
} 
LANGER, Máximo; LILLO, Ricardo, "Reforma a la justicia penal juvenil y adolescentes privados de libertad en Chile: Aportes empíricos para el debate”.

\section{Figura 3: Cantidad y porcentaje de privación de libertad juvenil pre y post sentencia entre 2003-2012}

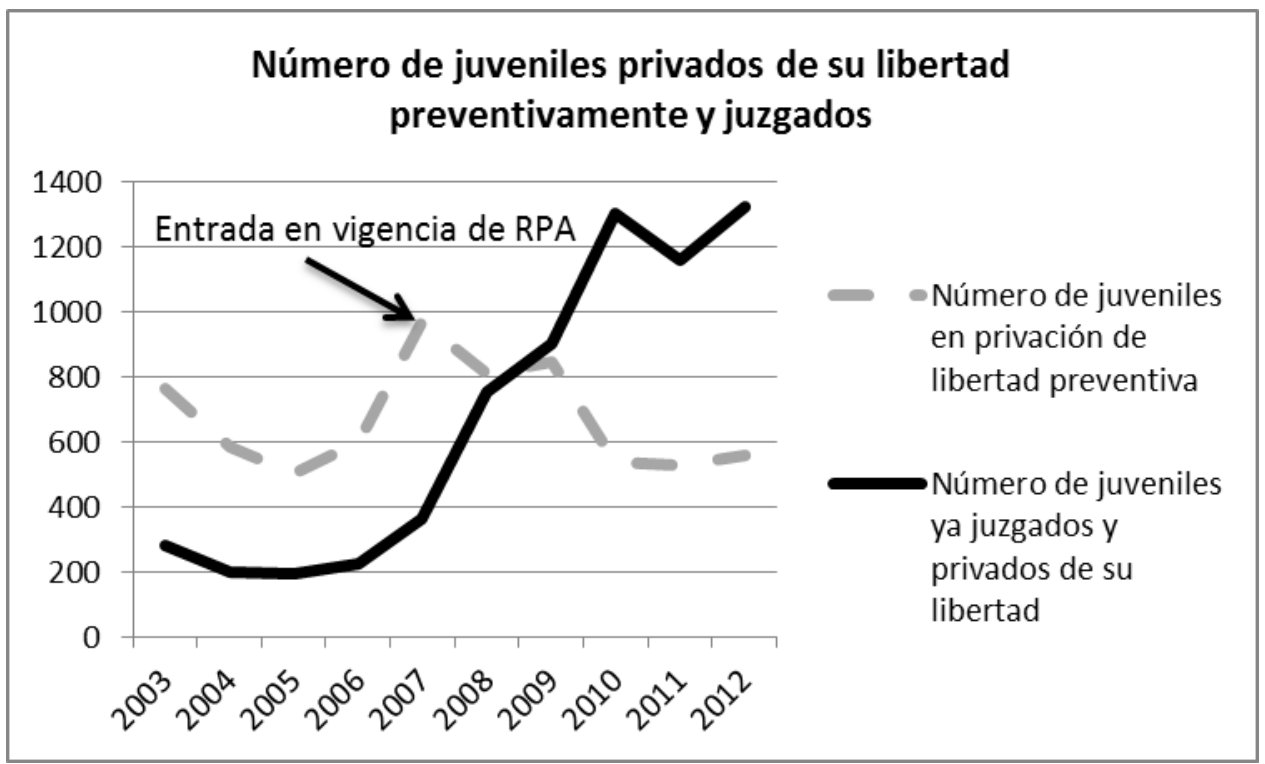

Fuente: DEPARTAMENTO DE ESTUDIOS, GENDARMERÍA DE CHILE, Compendio Estadístico

Penitenciario, Santiago: Gendarmería de Chile, 2010-2012.; SENAME, Boletín Estadístico Anual de los Niños(as) y Adolescentes Vigentes en la Red SENAME, 2003-2013, Santiago: Sename, 2003-2014. ${ }^{35}$

Para ilustrar este último punto y continuar con nuestro análisis, las siguientes tablas y figuras muestran el número de jóvenes en privación de libertad en el agregado y de acuerdo a los dos tipos de delitos más relevantes desde 2003 a 2012. ${ }^{36}$

\footnotetext{
${ }^{35}$ Se han obtenido los datos sobre el número de juveniles en prisión preventiva en el sistema correccional regular antes de que la Ley RPA entrara en efecto de los informes anuales de Gendarmería de Chile y no de los del SENAME puesto que los informes anuales del SENAME que hemos usado en el resto de este trabajo como fuente para el número de jóvenes privados de libertad no describían el número de jóvenes privados de su libertad preventivamente en el sistema correccional regular. Como consecuencia de usar diversas fuentes, el número total de juveniles en privación de libertad para los años previos a la entrada en vigencia de la reforma a la justicia adolescente exhibida en esta figura varía respecto al número usado en el resto de este trabajo. No obstante, la variación no es muy significativa (1051 en vez de 927 para el año 2003, 784 en vez de 799 para el 2004, 699 en vez de 762 para el 2005, 827 en vez de 848 para el 2006, y 1334 en vez de 1177 jóvenes para el año 2007). Más allá de lo anterior, en ambos casos el análisis es el mismo ya que en ambos casos es posible observar una tendencia creciente en la privación de libertad de jóvenes con posterioridad a la entrada en vigencia de la reforma a la justicia juvenil.

${ }^{36}$ Los informes anuales de SENAME son nuestra fuente para estos números sobre jóvenes en privación de libertad. Los nombres y tipos de categorías de jóvenes en confinamiento eran diferentes antes y después de la reforma a la justicia adolescente en Chile. De esta manera, hemos incluido en el total de jóvenes en privación de libertad a aquellos en "Centros de Observación y Diagnóstico" (COD), que hemos considerado como equivalente a una prisión preventiva. También hemos incluido en el número total de privados de libertad a aquellos en programas de "Rehabilitación Conductual Internado", medidas aplicadas a aquellos que eran encontrados culpables de una ofensa penal y eran menores a 16 o entre dicha edad y 17 años y declarados sin discernimiento bajo la Ley de Menores; y aquellos considerados por los datos del SENAME en "Secciones de Menores de Gendarmería de Chile" (donde eran enviados aquellos entre 16 y 17 años y declarados con discernimiento). Luego de la introducción de la reforma, se ha incluido en el total de jóvenes en privación de libertad a aquellos sujetos a "internación provisoria", considerada como equivalente a la prisión preventiva, y
} 
Polít. crim. Vol. 9, No 18 (Diciembre 2014), Art. 13, pp. 713-738.

[http://www.politicacriminal.cl/Vol_09/n_18/Vol9N18A13.pdf]

Tabla 3: Número total de jóvenes en privación de libertad y porcentaje de jóvenes en privación de libertad respecto del total de la población privada de libertad $\underline{(2003-2012)}$

\begin{tabular}{|c|c|c|c|c|c|c|c|c|c|c|}
\hline Datos & 2003 & 2004 & 2005 & 2006 & 2007 & 2008 & 2009 & 2010 & 2011 & 2012 \\
\hline $\begin{array}{c}\text { Jóvenes } \\
\text { privados de } \\
\text { su libertad }\end{array}$ & 927 & $799^{37}$ & 762 & 848 & 1177 & 1569 & 1750 & 1844 & 1690 & 1882 \\
\hline $\begin{array}{c}\text { Porcentaje } \\
\text { de privación } \\
\text { de libertad } \\
\text { jóvenes }\end{array}$ & 2.5 & 2.2 & 2 & 2.1 & 2.6 & 3.1 & 3.2 & 3.3 & 3.1 & 3.7 \\
\hline
\end{tabular}

Fuente: SENAME, Boletín Estadístico Anual de los Niños(as) y Adolescentes Vigentes en la Red SENAME, 2003-2013, Santiago: Sename, 2003-2014.

\section{Figura 4: Número de jóvenes en privación de libertad. Totalidad de delitos, robos y}

\section{homicidio entre 2003-2012}

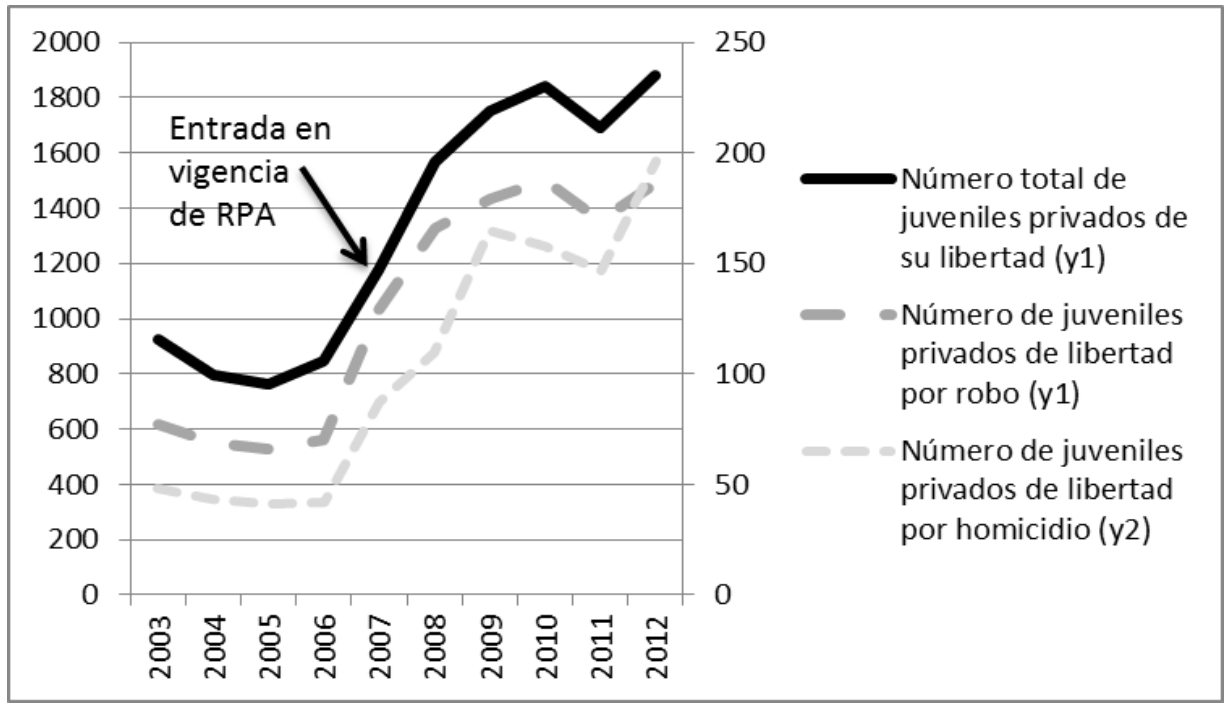

aquellos condenados y privados de su libertad al ser sentenciados en Regímenes Cerrado o Semicerrados (definidos en los artículos 16 y 17 de la Ley $\mathrm{N}^{\circ} 20.084$ ).

${ }^{37}$ En el documento: UNIVERSIDAD DIEGO PORTALES, FACULTAD DE DERECHO, Informe Anual de Derechos Humanos 2006. Hechos de 2005, Santiago: Ediciones Universidad Diego Portales, 2006, se exhibe una población juvenil total en privación de libertad para el año 2004 que es cercana a los 960 jóvenes en lugar de los 799 juveniles que nosotros reportamos en este trabajo (ver páginas 66 y 70-71 del informe citado). Esta diferencia puede ser parcialmente explicada por el hecho que mientras aquí usamos el reporte anual del SENAME que consistentemente reporta el número de jóvenes privados de libertad al 31 de diciembre de cada año, dicho informe en cuestión reporta datos de jóvenes en Centros de Observación y Diagnóstico y Centros de Rehabilitación Conductual al 30 de septiembre de 2004. Además, es posible que ese número indicado en el reporte se refiera al número total de jóvenes que fueron privados de libertad para esa fecha, aun cuando no lo podemos saber con certeza de lo descrito en el informe. En cambio, los números de nuestra Tabla 3 incluyen el número de jóvenes en "secciones juveniles" al 31 de diciembre de 2004, tal como es indicado en el informe anual del SENAME. En cualquier caso, las diferencias reportadas en estos números no implican un cambio a la sustancial tendencia al alza en la privación de libertad de jóvenes pre y post reforma a la justicia penal adolescente. 
LANGER, Máximo; LILLO, Ricardo, "Reforma a la justicia penal juvenil y adolescentes privados de libertad en Chile: Aportes empíricos para el debate".

Fuente: SENAME, Boletín Estadístico Anual de los Niños(as) y Adolescentes Vigentes en la Red SENAME, 2003-2013, Santiago: Sename, 2003-2014.

La privación de libertad de jóvenes aumentó sustancialmente desde el 2003 al 2012. Esta tendencia al alza en los niveles de confinamiento comenzó en el año 2007, año en que la ley que estableció la reforma a la justicia penal adolescente entró en vigencia, y siguió creciendo marcadamente hasta el año 2010. El número total de jóvenes en privación de libertad aumentó un 103\% entre 2003 y 2012, y 121\% del 2006 (el año anterior a la entrada en vigencia de la reforma) al 2012. El porcentaje de privación de libertad de jóvenes respecto del total de la población recluida (i.e. jóvenes y adultos incluidos) también creció de 2,5\% en 2003 y de 2,1\% en 2006 a 3,7\% en el 2012 (Tabla 3 y Figura 4).

Como indica la Figura 4, el incremento en los niveles de privación de libertad juvenil es explicado casi en su totalidad por el incremento en los privados de libertad por los delitos de robo y homicidio. Mientras que el número de jóvenes privados de libertad por el delito de robo subió de 556 jóvenes en 2006 a 1487 en 2012, el número de jóvenes privados de libertad por homicidio subió de 42 en 2006 a 196 en 2012. Estas dos categorías representaron el 89\% del total de la población adolescente privada de su libertad en 2012 (Figura 4).

Para analizar qué factores han llevado a este incremento absoluto y relativo de los jóvenes privados de su libertad, es importante observar, en primer lugar, que los niveles del crimen juvenil o al menos de casos relacionados con jóvenes que llegaron al sistema de justicia no explican este incremento (Figura 5).

Figura 5: Arrestos por robo y homicidio de personas menores a 20 años $\underline{(2003-2012)}$

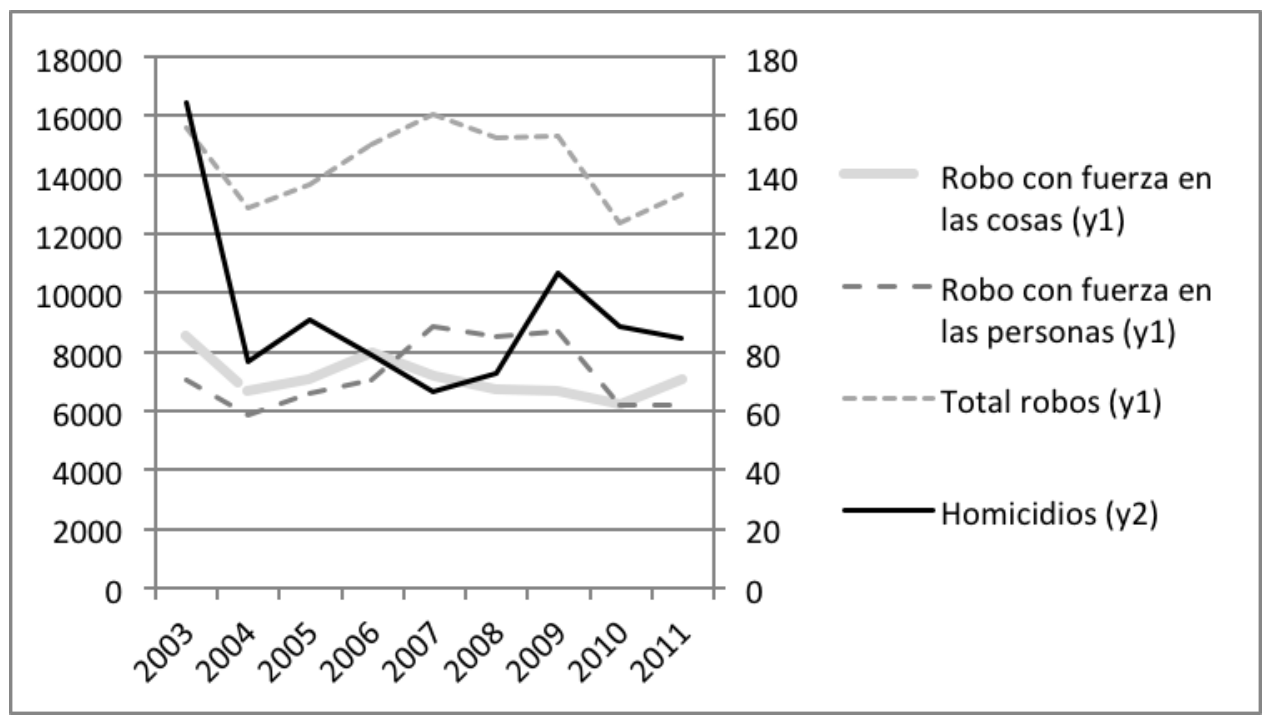

Fuente: FUNDACIÓN PAZ CIUDADANA, Anuario de Estadísticas Criminales 2011. Santiago, Fundación Paz ciudadana, 2011. 
El número de arrestos de jóvenes menores de 20 años por robo y homicidio disminuyó en el período 2003-2011. Si tomamos el año 2006 como inicio, los arrestos por homicidio se incrementaron $7,6 \%$ (de 79 a 85 casos), por robo disminuyeron $11,6 \%$, por robo con fuerza en las cosas disminuyeron $(11,4 \%)$ y aquellos con fuerza en las personas en un $11,8 \%$ (Figura 5). ${ }^{38}$

Dado que no hay indicaciones de que haya habido un incremento en los arrestos de jóvenes infractores en el período en cuestión y dada la falta de otras explicaciones alternativas, es razonable inferir que la reforma a la justicia penal adolescente de 2007 ha contribuido al aumento de la privación de libertad de dicho grupo de la población. ${ }^{39}$

Una primera observación en este sentido es que los aspectos procesales de la reforma a la justicia penal adolescente no parecen poder explicar completamente el incremento en los niveles de privación de libertad de los jóvenes infractores. Tal como lo mencionamos, esta reforma trajo consigo profundos cambios procesales al hacer aplicable a los adolescentes los principios de la reforma procesal penal que entró en vigencia plena para los adultos en el año 2005. La reforma procesal penal implicó no solo mayores derechos en el proceso penal para los adolescentes imputados por la comisión de delitos, sino también otras características procesales e institucionales que podrían explicar este incremento en los niveles de privación de libertad de los juveniles. Estudios empíricos sobre la reforma procesal penal sugieren que esta incrementó la eficiencia de la administración de justicia en Chile al reducir sustancialmente el tiempo entre el arresto (u otras maneras de iniciar el procesal penal) y la sentencia mediante la desformalización de la fase de investigación previa y la introducción de mecanismos como el juicio simplificado, el procedimiento monitorio, etc. ${ }^{40}$ Esta reducción en la duración del proceso liberó recursos humanos y materiales y así permitió al sistema procesar más casos y lograr más sentencias -incluyendo

\footnotetext{
${ }^{38}$ Los datos sobre jóvenes en la Figura 5 son imperfectos porque también incluyen arrestos de individuos entre 18 y 19 años. Aquí se utilizan porque ellos son la única fuente de datos por tipo de delito que hemos podido obtener. Una alternativa podría haber sido usar los datos sobre jóvenes con contacto formal con la policía para todos los delitos en el mismo período que tiene la Oficina de Naciones Unidas para la Droga y el Delito. Pero, de todos modos, estos últimos datos van en la misma dirección que la reportada por nosotros mostrando una disminución de $11 \%$ para los juveniles.

${ }^{39}$ Otra explicación considerada durante este análisis fue el inicio de la administración del ex Presidente Sebastián Piñera en marzo de 2010. Durante dicho período, mediante un discurso anti delincuencia y de crítica hacia la labor de los jueces, se presionó por un cambio en la política criminal de manera de que los actores del sistema penal incrementaran los niveles de persecución y el uso de penas privativas de libertad. Ver: Diario La Tercera, 15 de abril, 2010. Disponible en: http://www.latercera.com/contenido/674_251648 9.shtml; El Quinto Poder, 3 de marzo, 2014. Disponible en: http://www.elquintopoder.cl/politica/pinera-y-su-curioso-concepto-de-justicia/; El Mostrador, 26 de febrero, 2014. Disponible en:

http://www.lasegunda.com/Noticias/Politica/2014/02/917180/presidente-critica-a-fiscales-jueces-de-garantiay-tribunales-por-seguridad-ciudadana. Sin embargo, esta hipótesis no es consistente con nuestros datos. Tal como se muestra en la figura 4, el incremento en los niveles de privación de libertad de adolescentes se presenta hasta el 2010, año en que el ex Presidente Piñera comenzó su período, para luego estabilizarse e incluso disminuir en los años posteriores. Los datos disponibles entonces indican que el discurso anti delincuencia en dicha administración no explica el incremento en el uso de medidas privativas de libertad respecto de adolescentes que aquí se analiza.

${ }^{40}$ Ver, por ej.: por ej., DUCE, La Prisión Preventiva en Chile, cit. nota ${ }^{\circ} 33$.
} 
LANGER, Máximo; LILLO, Ricardo, "Reforma a la justicia penal juvenil y adolescentes privados de libertad en Chile: Aportes empíricos para el debate".

aquellas que impusieron penas privativas de libertad. Adicionalmente, la reforma procesal penal habría fortalecido a las instituciones encargadas de la persecución al crear el Ministerio Público y al aumentar la capacidad de la policía.

El sistema acusatorio fue introducido para la población adulta de manera gradual por región a partir del año 2000 para culminar con su entrada en vigencia en la Región Metropolitana (la mayor del país en términos de población) en el año 2005. En el caso de los adolescentes, los efectos de la reforma procesal penal comenzaron con la entrada en vigencia de la Ley RPA en junio de 2007.

Para evaluar si es que los aspectos procesales de la nueva justicia penal adolescente contribuyeron en el incremento de los niveles de privación de libertad de adolescentes observado, es entonces útil estudiar los datos sobre la tasa de privación de libertad de adultos y jóvenes entre los años 2003 a 2012 (Figura 6).

Figura 6: Tasa de privación de libertad entre jóvenes y adultos entre 2003-2012

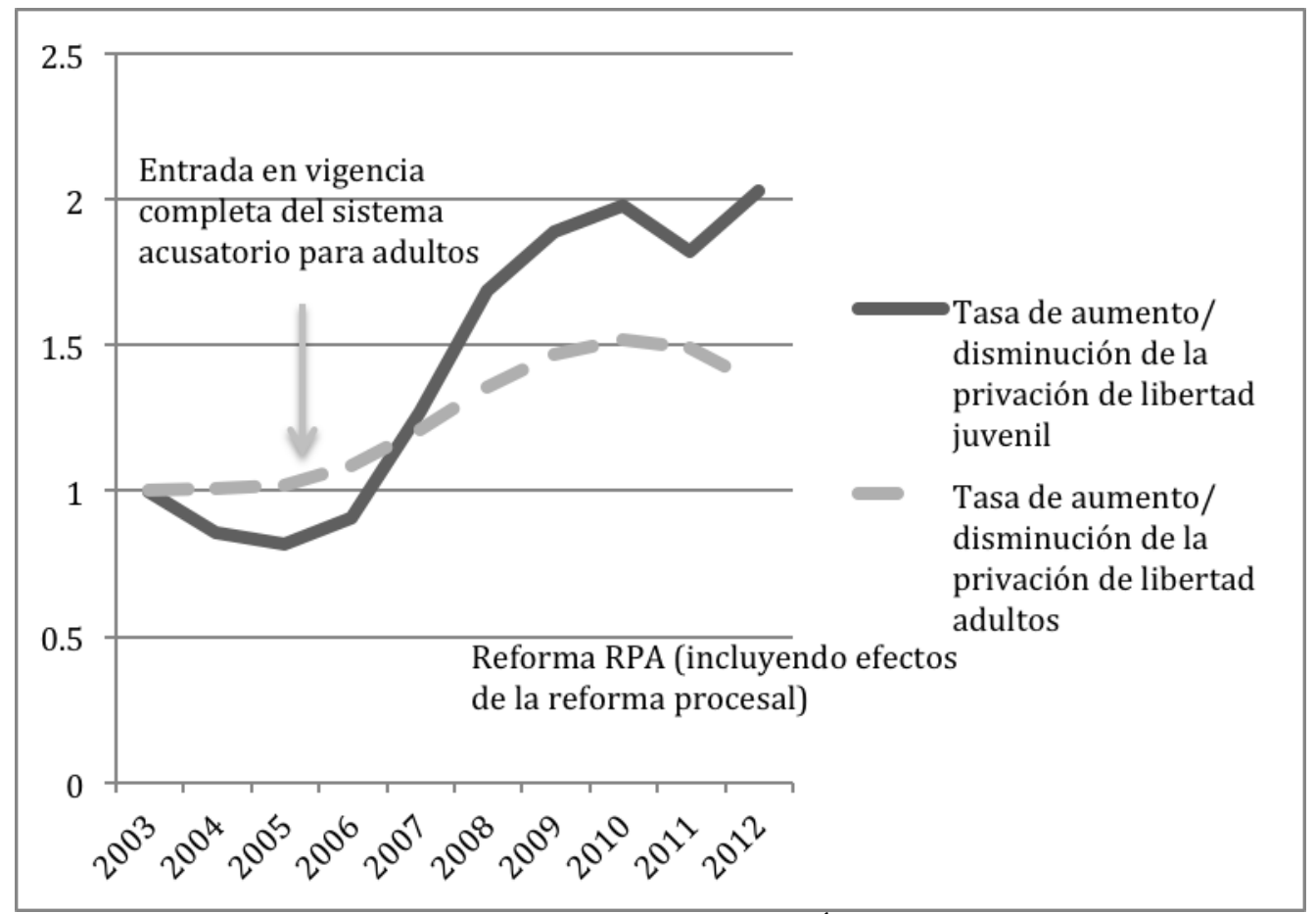

Fuente: DEPARTAMENTO DE ESTUDIOS, GENDARMERÍA DE CHILE, Compendio Estadístico Penitenciario, Santiago: Gendarmería de Chile, 2010-2012.; SENAME, Boletín Estadístico Anual de los Niños(as) y Adolescentes Vigentes en la Red SENAME, 2003-2013, Santiago: Sename, 2003-2014.

Si se toma el año 2003 como punto de partida, con la entrada en vigencia completa del sistema acusatorio en el año 2005, la tasa de adultos privados de libertad aumentó un 37\% entre los años 2003 a 2012. En el caso de los adolescentes, y nuevamente tomando como punto de partida el año 2003, la población juvenil privada de libertad aumentó un 103\% en el mismo período. Es, entonces, posible que la implementación de la reforma procesal penal haya sido un factor que contribuyó al incremento de privación de libertad para adultos y 
jóvenes. Sin embargo, la implementación de la reforma procesal penal y sus efectos tanto respecto de adolescentes como de adultos no pueden explicar por qué la privación de libertad de los primeros aumentó 2,78 veces más que la tasa de privación de los adultos en este período (Figura 6).

Además, esta diferencia entre el incremento entre el encarcelamiento de adultos y jóvenes es aún más destacable si tomamos en consideración que mientras las tasas de arresto no parecen explicar el incremento de privación de libertad en el caso de los jóvenes (como ya hemos visto), sí parecen hacerlo en el caso de los adultos, tal como muestra el siguiente gráfico (Figura 7).

\section{Figura 7: Privación de libertad de adultos y arrestos de mayores de 19 años (total} país, y en robos y drogas) entre 2003-2011

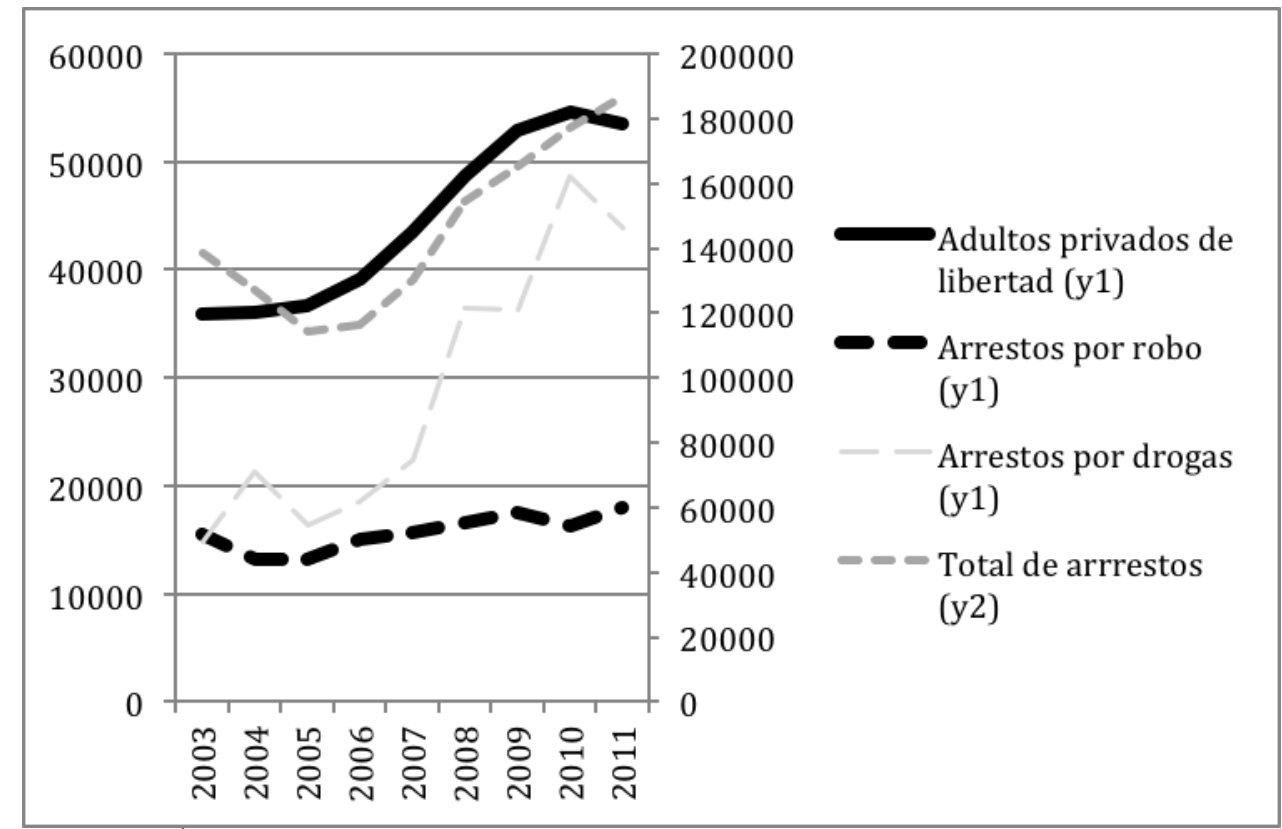

Fuente: FUNDACIÓN PAZ CIUDADANA, Anuario de Estadísticas Criminales 2011. Santiago, Fundación Paz ciudadana, 2011.

El incremento en la curva de arrestos de personas mayores de 19 años calza casi perfectamente con el incremento en la curva de privación de libertad de adultos. Mientras que el total de arrestos de personas mayores de 19 años aumentó un 47\% (de 127247 a 187273 arrestos) entre el 2004 y el 2011, el encarcelamiento lo hizo en un $48 \%$ en el mismo período (de 36123 a 53606 casos) (Figura 7).

Si el incremento en los arrestos de los adultos puede explicar el incremento en la privación de libertad de los adultos, al menos en una parte sustancial, entonces la introducción del sistema acusatorio no explicaría dicho incremento. Por ello, a menos que el sistema acusatorio haya afectado a jóvenes y adultos de forma completamente distinta, la introducción de dicho sistema tampoco permitiría explicar (completamente) el incremento en la privación de libertad en el caso de los jóvenes. 
LANGER, Máximo; LILLO, Ricardo, "Reforma a la justicia penal juvenil y adolescentes privados de libertad en Chile: Aportes empíricos para el debate".

Sin embargo, es posible que sistema acusatorio haya afectado de manera diferenciada la privación de libertad de adultos y jóvenes, dada la diferente composición del conjunto de casos de estos dos grupos etarios. Los casos de robo, un tipo de delito que es considerado comparativamente de fácil persecución y enjuiciamiento, dan cuenta del 75 a $80 \%$ de la privación de libertad entre los jóvenes (Figura 4). En contraste, el robo y hurto representan el 50\% de la privación de libertad entre adultos, y los delitos relacionados con drogas delitos considerado como de mayor complejidad en términos de investigación, persecución y juicio en comparación con el robo- representan más del 15\% de los casos de privación de libertad de adultos. A su vez, mientras que los arrestos por robo en adultos aumentaron un $36 \%$, aquellos relacionados con drogas lo hicieron en un 198\% entre 2003 y 2011. Es entonces posible que la introducción del sistema acusatorio en Chile haya contribuido al incremento de la privación de libertad de jóvenes más que en el caso de los adultos porque implicó cambios que hicieron al sistema más eficiente particularmente en la investigación, persecución y juicio de delitos como el robo que es aquél que representa la mayoría de las causas de privación de libertad entre adolescentes.

Pero incluso aun cuando el sistema acusatorio haya afectado a adultos y jóvenes de diferente manera, es improbable que este sea el único aspecto de la reforma a la justicia adolescente que explique el incremento en los niveles de privación de libertad de adolescentes luego de la introducción de la reforma, dado el gran porcentaje de aumento de la privación de adolescentes en comparación con los adultos y dado que los arrestos de menores de 20 años han disminuido, mientras que los arrestos de mayores de 20 han aumentado sustancialmente.

Otros aspectos de la reforma a la justicia penal de adolescente podrían entonces explicar, al menos parcialmente, dicho aumento. Tal como lo mencionamos, la Ley RPA estuvo particularmente orientada a reemplazar el antiguo modelo tutelar basado en la utilización de "medidas de protección" sobre jóvenes criminalmente inimputables por un modelo que, siguiendo estándares internacionales en la materia, considera a estos individuos como responsables por sus propios actos, aun cuando estén sujetos a reglas especiales. Parte de los antiguos jueces de los "Juzgados de Menores" se retiraron o fueron transferidos a la justicia civil (o a otras materias) y un nuevo grupo de actores, fiscales y jueces, capacitados y especializados en el nuevo sistema, comenzaron a manejar este grupo de casos desde que la reforma comenzó en 2007.

Es entonces posible que el cambio de un paradigma tutelar a uno de responsabilidad penal para los adolescentes haya llevado a un mayor uso de la privación de libertad contra adolescentes porque ha dejado más lugar para que los fiscales y los jueces que toman decisiones sobre estos casos tomen en cuenta consideraciones retributivas y de prevención especial negativa. Este resultado no sería necesariamente contrario a los fines de la RPA dado que, como ya señalamos, un grupo de actores políticos apoyó la reforma porque creyó que el viejo sistema no era suficientemente eficiente en la persecución de los delitos cometidos por adolescentes. Pero este resultado debería ser desalentador para aquellos que apoyaron la reforma pensando que llevaría a un uso menor de la privación de libertad de adolescentes y a una aplicación más estricta del principio de mínima intervención. 
Aunque no es posible encontrar información expresa sobre las posiciones de fiscales y jueces sobre este tema (o que se puedan reflejar en la justificación de sus actuaciones, como las sentencias en el caso de los jueces), conversaciones informales con algunos fiscales y jueces especializados en la materia nos han sugerido que estos tienden a solicitar o decretar medidas privativas de libertad ante lo que perciben como la falta de eficacia de las medidas alternativas, ya que, de acuerdo a las percepciones de estos operadores del sistema de justicia, las medidas alternativas no estarían cumpliendo con los fines de resocialización de los adolescentes infractores, sino que, por el contrario, solo estarían contribuyendo a su reincidencia delictual o a una sensación de impunidad. En consecuencia, se ha criticado también que la inoperancia de estas medidas ha dado lugar a mayores niveles de quebrantamiento y reincidencia. ${ }^{41}$

El propio Poder Judicial sí ha señalado lo que considera algunos problemas en la ejecución de las sanciones respecto de adolescentes, señalamientos reflejan percepciones similares a las de los operadores del sistema de justicia adolescente mencionadas en el párrafo precedente. Por ejemplo, en un informe publicado en el marco de la Comisión de Constitución, Legislación, Reglamento y Justicia del Senado, el Presidente del Poder Judicial consideró que ha habido problemas en la práctica cuando el adolescente no se presenta a la entrevista para la elaboración del plan de intervención individual utilizado en sanciones como la libertad asistida, ya que se ha entendido que la no presentación no constituye una situación de quebrantamiento, e, incluso cuando hay una orden de detención, esta no faculta para disponer el traslado compulsivo del adolescente a la institución encargada de realizar el plan de intervención. ${ }^{42}$ Asimismo, en referencia a las penas de prestación de servicios en beneficio a la comunidad, el Fiscal Nacional ha señalado que muchos adolescentes, a los cuales se les ha impuesto la obligación de prestar servicios en beneficio de la comunidad, prefieren quebrantar esa pena para que les sea sustituida por la de libertad asistida, la cual frecuentemente queda reducida a un mero sistema de citaciones y firmas. ${ }^{43}$ A su vez, en relación a la internación en régimen semicerrado, se ha señalado que habría un escaso control en el sistema de cumplimiento de esta sanción y una falta de una oferta programática durante la jornada diurna que, en los hechos, estaría transformando a la internación en régimen semicerrado en una pena de reclusión nocturna. ${ }^{44}$ Por su parte, un informe de UNICEF señala que, en las entrevistas realizadas para el informe, los jueces expresamente indicaron desconfiar de la información presentada por los encargados de la ejecución de la sanción y que no estaban seguros de la efectividad y calidad de las actividades realizadas con los jóvenes. ${ }^{45}$ Es entonces posible que esta percepción de los operadores del sistema de justicia sobre las medidas y sanciones respecto de adolescentes haya tenido un efecto en el aumento de la tasa de privación de libertad de los adolescentes. En cualquier caso, sin tener datos a nivel del caso individual sobre medidas pre and post reforma respecto de adolescentes y otras variables con los que no contamos, la hipótesis que los aspectos sustantivos de la reforma han contribuido al aumento de la privación de

${ }^{41}$ SENADO, Informe de la Comisión de Constitución, Legislación, Reglamento y Justicia, Boletín $N^{\circ} S$ 1.555-14, Valparaíso: Senado, 2014, p. 319.

${ }^{42}$ SENADO, Informe, cit. nota $\mathrm{n}^{\circ} 41$, p. 20.

${ }^{43}$ SENADO, Informe, cit. nota $n^{\circ} 41$, p. 48.

${ }^{44}$ SENADO, Informe, cit. nota $\mathrm{n}^{\circ} 41$, p. 48.

${ }^{45}$ SENADO, Informe, cit. nota ${ }^{\circ} 41$, p. 165. 
LANGER, Máximo; LILLO, Ricardo, "Reforma a la justicia penal juvenil y adolescentes privados de libertad en Chile: Aportes empíricos para el debate".

libertad de adolescentes solo puede ser testeada de modo indirecto, como lo hemos hecho en este trabajo.

En este sentido, es importante observar que los datos sobre las medidas aplicadas respecto de adultos y adolescentes luego de la entrada en vigencia de la RPA también son consistentes con la hipótesis de que las decisiones de los fiscales y los jueces bajo la Ley RPA han llevado a un aumento en la privación de libertad de adolescentes. En primer lugar, el Ministerio Público ha utilizado archivo provisional, que no requiere aprobación judicial, en mucha mayor medida para los adultos que para los adolescentes (Figura 8).

Figura 8: Archivo provisional, Ley RPA y adultos entre 2008 -2013

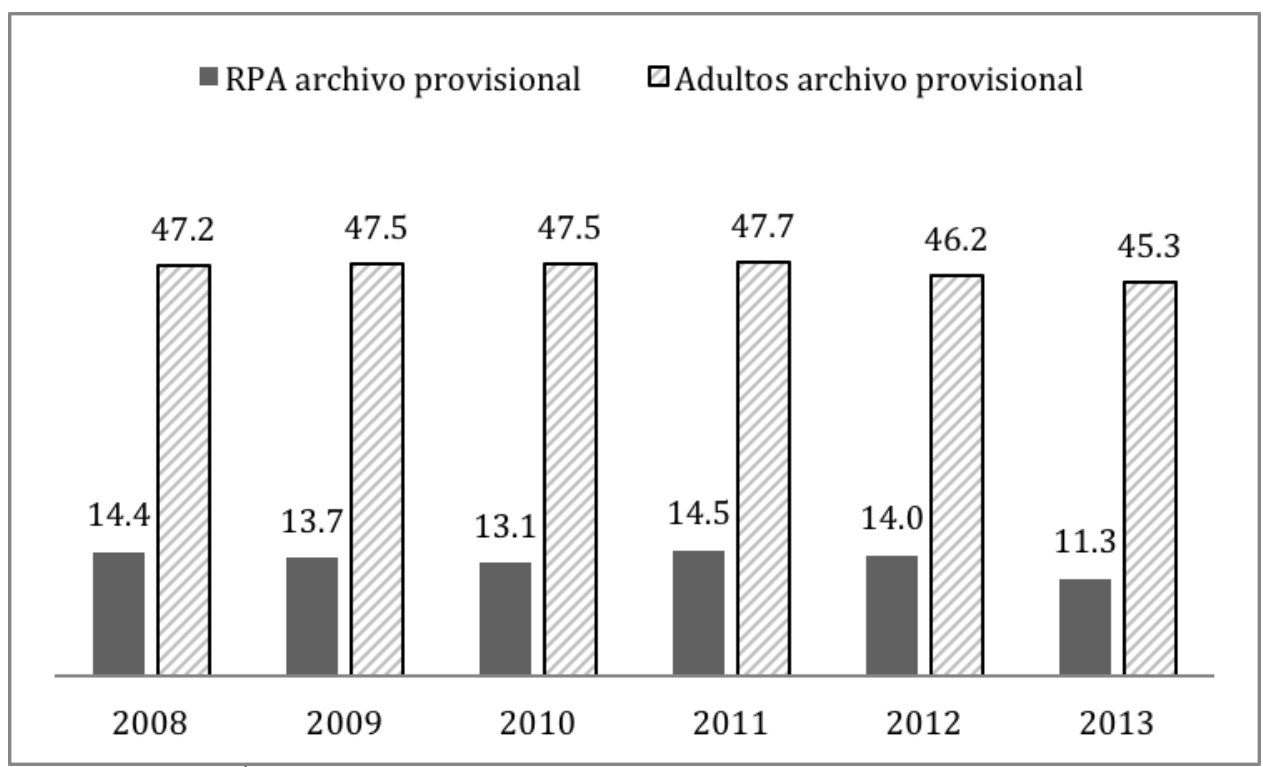

Fuente: MINISTERIO PÚBLICO, Boletines Estadísticos Anuales 2008-2013. Santiago, Ministerio Público, 2008-2013.

Si se consideran los años a partir del primer año completo con la Ley RPA en vigencia, las causas del Ministerio Público terminadas por las denominadas "salidas judiciales" (o que requieren aprobación judicial) en causas bajo la Ley RPA son bastante superiores en comparación con los adultos (Figura 9). 
Polít. crim. Vol. 9, № 18 (Diciembre 2014), Art. 13, pp. 713-738.

[http://www.politicacriminal.cl/Vol_09/n_18/Vol9N18A13.pdf]

Figura 9: Salidas judiciales RPA vs Adultos (total país - RPA) (2008-2013)

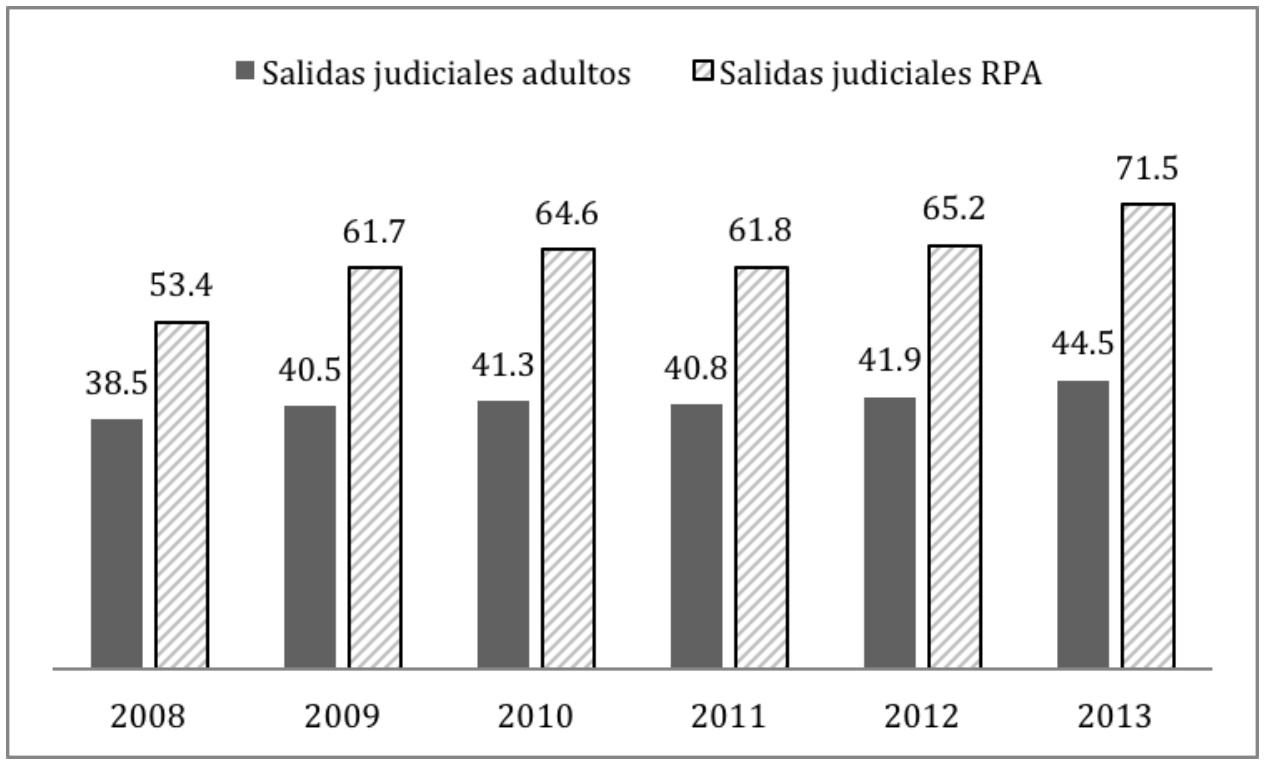

Fuente: MINISTERIO PÚBLICO, Boletines Estadísticos Anuales 2008-2013. Santiago, Ministerio Público, 2008-2013.

Dentro de las salidas judiciales, las más importantes en términos porcentuales dentro del total país son la sentencia definitiva condenatoria y la suspensión condicional del procedimiento. Como puede observarse en la Figura 10, un mucho mayor porcentaje de las causas de adolescentes llegan a sentencia condenatoria que las causas de adultos en todo el período observado (2008-2013).

Figura 10: Porcentajes de sentencias condenatoria, adultos y Ley RPA entre 2008$\underline{2013}$

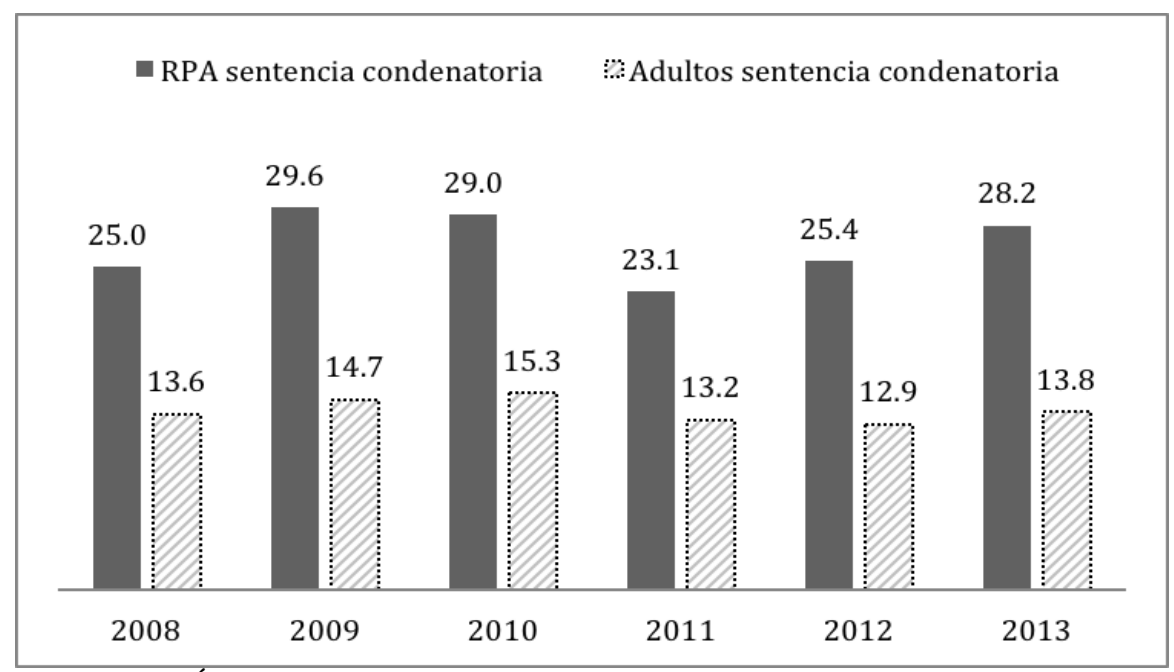

Fuente: MINISTERIO PÚBLICO, Boletines Estadísticos Anuales 2008-2013. Santiago, Ministerio Público, 2008-2013. 
LANGER, Máximo; LILLO, Ricardo, "Reforma a la justicia penal juvenil y adolescentes privados de libertad en Chile: Aportes empíricos para el debate".

Es posible entonces, que este cambio de paradigma respecto de jóvenes infractores, desde uno de protección a uno de responsabilidad, haya llevado a un mayor uso de la privación de libertad respecto de adolescentes lo que se expresaría en la manera en que los nuevos actores llevan este tipo de casos. El mayor uso del archivo provisional para adultos y el mayor uso de salidas judiciales y de sentencias condenatorias para adolescentes serían consistentes con esta hipótesis.

En cualquier caso, sea por sus innovaciones procesales, sustantivas o ambas, nuestros datos sugieren que la reforma a la justicia penal juvenil ha contribuido a un aumento de los niveles absolutos y relativos de la privación de libertad de adolescentes.

\section{Conclusiones}

Aproximándose a la primera década desde la entrada en vigencia de la Ley de Responsabilidad Penal Adolescente es momento de reflexionar y evaluar sus resultados. Para ello, la producción, levantamiento y análisis empírico de los datos sobre su funcionamiento, y, en particular, la comparación con la situación previa a la reforma son extremadamente importantes. Es en base a ellos que los actores relevantes en la materia podrán incorporar los cambios que sean necesarios.

Una primera conclusión de este trabajo es que la reforma de la justicia penal adolescente implicó que los porcentajes de adolescentes en internamiento provisorio disminuyeran de manera importante, pasando de representar aproximadamente un $70 \%$ de la población juveniles privada de libertad a cerca del $30 \%$. Aun cuando esta cifra sigue siendo superior a los porcentajes de adultos, significa una baja importante de los presos sin condena.

Sin embargo, luego de la entrada en vigencia de la reforma a la justicia penal juvenil, los datos de las diversas instituciones vinculadas a la justicia adolescente muestran que las tasas totales y relativas de privación de libertad de adolescentes han aumentado. Este trabajo ha mostrado que este aumento no se ha debido a una mayor cantidad de arrestos de jóvenes. Nuestro análisis sobre la reforma a la justicia penal adolescente sugiere que esta ha probablemente tenido un impacto en este incremento en la privación de libertad de adolescentes en Chile.

Si bien los adolescentes en Chile son todavía confinados a menores tasas que los adultos una vez que entran en contacto formal con la policía, luego de la implementación de la Ley RPA los niveles absolutos y relativos de privación de libertad entre los adolescentes aumentaron significativamente. En sentido, el principio de mínima intervención se ha aplicado menos estrictamente luego de la introducción de la Ley RPA.

Entre aquellos que apoyaron la reforma esperando que llevara a una persecución penal más eficiente de los jóvenes infractores, habrá muchos que estarán satisfechos con el aumento de la tasa de privación de libertad de jóvenes en los términos descritos. Entre aquellos que apoyaron la reforma porque creyeron que disminuiría las tasas absolutas y relativas de adolescentes privados de su libertad, este resultado será desalentador. Pero parte de este grupo tal vez todavía defienda la reforma a la justicia penal juvenil argumentando que ha 
mejorado el tipo de privación de libertad de adolescentes porque ya no se coloca a adolescentes en establecimientos carcelarios para adultos, que se ha reducido el margen para decisiones arbitrarias por parte de los jueces, y que a los jóvenes se les otorga ahora mayores garantías procesales que antes.

Nuestro objetivo principal no ha sido, sin embargo, zanjar esta discusión, sino aportar datos y promover más estudios empíricos que enriquezcan el análisis académico y la discusión pública sobre el tratamiento de adolescentes presuntamente infractores por parte del sistema legal de Chile.

\section{BIBLIOGRAFÍA}

BELOFF, Mary; LANGER, Máximo, "Myths and Realities of Juvenile Justice in Latin America”, en: LANGER, Máximo; TANENHAUS, David S.; ZIMRING, Franklin D., (Compiladores), Juvenile Justice in Global Perspective: Estados Unidos: NYU Press, 2015 (en prensa).

BERRÍOS, Gonzalo, "La ley de responsabilidad penal del adolescente como sistema de justicia: análisis y propuestas", Polít. crim. Vol. 6, No 11, Art. 6 (2011), pp. 163-191.

BIBLIOTECA DEL CONGRESO NACIONAL DE CHILE, Historia de la Ley 20.084, Establece un sistema de responsabilidad de los adolescentes por infracciones a la ley penal, Santiago: Biblioteca del Congreso Nacional de Chile, 2005.

CENTRO DE ESTUDIOS DE JUSTICIA DE LAS AMÉRICAS (CEJA), Prisión Preventiva y Reforma Procesal Penal en América Latina. Evaluación y Perspectivas, Santiago: CEJA, 2009.

CILLERO BRUÑOL, Miguel, "De la Tutela a las Garantías: Consideraciones sobre el Proceso Penal y la Justicia de Adolescentes", Revista de Derechos del Niño, $\mathrm{N}^{\circ} 2$ (2004), pp. 53-86.

CILLERO BRUÑOL, Miguel; BERNALES, Martín, "Derechos humanos de la infancia/adolescencia en la justicia "penal de menores" de Chile: evaluación y perspectivas", Revista de Derechos del Niño, № 1 (2002), pp. 9-40.

CILLERO BRUÑOL, Miguel; ESPEJO YAKSIC, Nicolás, "Derechos de los Adolescentes Privados de Libertad en Chile: En búsqueda de la tutela judicial efectiva", Revista General de Derecho Penal, N 9 (2008), pp. 1-12.

CORPORACIÓN OPCIÓN; UNICEF, ;Conoce Tus Derechos! Manual sobre la Ley de Responsabilidad Penal de Adolescentes, Santiago: UNICEF y Corporación Opción, 2009.

COUSO SALAS, Jaime; DUCE JULIO, Mauricio, Juzgamiento penal de adolescentes, Santiago: LOM ediciones, 2013.

DEFENSORÍA PENAL PÚBLICA, 3 años de vigencia Ley de responsabilidad penal del adolescente 8 de Junio de 2007 a 7 de Junio de 2010. Santiago: Defensoría Penal Pública, 2011.

DEPARTAMENTO DE ESTUDIOS, DEFENSORIA PENAL PÚBLICA, Informe Estadístico Primer año de vigencia Ley de Responsabilidad Penal Adolescente (8 junio 2007 a 7 junio 2008), Santiago: Defensoría Penal Pública, 2008. 
LANGER, Máximo; LILLO, Ricardo, "Reforma a la justicia penal juvenil y adolescentes privados de libertad en Chile: Aportes empíricos para el debate".

DEPARTAMENTO DE ESTUDIOS, GENDARMERÍA DE CHILE, Compendio Estadístico Penitenciario 2010, Santiago: Gendarmería de Chile, 2010.

DUCE JULIO, Mauricio, "El proceso establecido en el Proyecto de Ley que crea un sistema de responsabilidad de los adolescentes por infracciones a la ley penal: avances y problemas", Revista de Derechos del Niño, № 2 (2004), pp. 99-114.

DUCE JULIO, Mauricio; RIEGO RAMÍREZ, Cristian, La Prisión Preventiva en Chile: Análisis de los Cambios Legales y su Impacto, Santiago: Ediciones Universidad Diego Portales, 2011.

ESPEJO YAKSIC, Nicolás, Hacia una Reforma Integral del Sistema Penal de Adolescentes en Chile: el Desafío de la Especialización, Serie reflexiones Infancia y adolescencia $N^{\circ} 18$, Santiago: UNICEF, 2014.

FUNDACIÓN PAZ CIUDADANA, Anuario de Estadísticas Criminales 2011. Santiago, Fundación Paz ciudadana, 2011.

LANGER, Máximo, Revolución en el Proceso Penal Latinoamericano: Difusión de Ideas Legales desde la Periferia, Santiago: Centro de Estudios de Justicia de las Américas (CEJA), 2008.

MINISTERIO PÚBLICO, Boletines Estadísticos Anuales 2008-2013. Santiago, Ministerio Público, 2008-2013.

RIEGO RAMÍREZ, Cristián, "El Proceso de Reforma del Procedimiento Penal Chileno", en: HURTADO POZO, José (Dir.); SAN MARTÍN CASTRO, César (Coord.), La Reforma del Proceso Penal Peruano, Anuario de Derecho Penal 2004, Lima: Fondo Editorial de la Pontificia Universidad Católica del Perú, 2004, pp. 373-400.

SENADO, Informe de la Comisión de Constitución, Legislación, Reglamento y Justicia, Boletín $N^{\circ} S$ 1.555-14, Valparaíso: Senado, 2014.

SENAME, Boletín Estadístico Anual de los Niños(as) y Adolescentes Vigentes en la Red SENAME, 2003-2013, Santiago: Sename, 2003-2014.

, Informe de Diagnóstico de la Implementación de la Ley 20.084 Junio 2007Marzo 2010, Santiago: Sename, 2010.

UNIVERSIDAD DIEGO PORTALES, FACULTAD DE DERECHO, Informe Anual de Derechos Humanos 2006. Hechos de 2005, Santiago: Ediciones Universidad Diego Portales, 2006. 